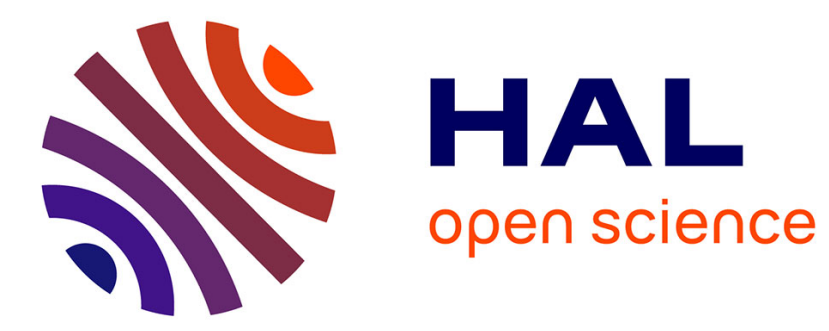

\title{
Photooxidation Responsive Elastin-Like Polypeptide Conjugates for Photodynamic Therapy Application
}

Vusala Ibrahimova, José A González-Delgado, Manon Levêque, Tomas Torres, Elisabeth Garanger, Sébastien Lecommandoux

\section{- To cite this version:}

Vusala Ibrahimova, José A González-Delgado, Manon Levêque, Tomas Torres, Elisabeth Garanger, et al.. Photooxidation Responsive Elastin-Like Polypeptide Conjugates for Photodynamic Therapy Application. Bioconjugate Chemistry, 2021, 10.1021/acs.bioconjchem.1c00251 . hal-03283784

\section{HAL Id: hal-03283784 \\ https://hal.science/hal-03283784}

Submitted on 12 Jul 2021

HAL is a multi-disciplinary open access archive for the deposit and dissemination of scientific research documents, whether they are published or not. The documents may come from teaching and research institutions in France or abroad, or from public or private research centers.
L'archive ouverte pluridisciplinaire HAL, est destinée au dépôt et à la diffusion de documents scientifiques de niveau recherche, publiés ou non, émanant des établissements d'enseignement et de recherche français ou étrangers, des laboratoires publics ou privés.

\section{(1)(1) $\$(0)$}

Distributed under a Creative Commons Attribution - NonCommercial - ShareAlikel 4.0 


\section{Photooxidation responsive elastin-like polypeptide}

\section{conjugates for PDT application}

Vusala Ibrahimova, ${ }^{\dagger}$ José A. González-Delgado, ${ }^{\ddagger}$ Manon Levêque, ${ }^{\dagger}$ Tomas Torres, ${ }^{* \dagger}$, Il, §

Elisabeth Garanger, ${ }^{*}$ and Sébastien Lecommandoux*†

${ }^{\dagger}$ Univ. Bordeaux, CNRS, Bordeaux INP, LCPO, UMR 5629, F-33600, Pessac, France

* Departamento de Química Orgánica, Universidad Autónoma de Madrid, 28049 Madrid, Spain

" IMDEA-Nanociencia, Campus de Cantoblanco, 28049 Madrid, Spain

$\S$ Institute for Advanced Research in Chemical Sciences (IAdChem), Universidad Autónoma de Madrid, 28049 Madrid, Spain

Corresponding authors: lecommandoux@enscbp.fr; garanger@enscbp.fr;

tomas.torres@uam.es 
ABSTRACT: Stimuli-responsive recombinant elastin-like polypeptides (ELPs) are artificial protein polymers derived from the hydrophobic domain of tropoelastin that have attracted significant interest for drug delivery and tissue engineering applications. In the present study, we have conjugated a photosensitizer (PS) to a hydrophobic methionine-containing ELP scaffold, which upon reaction with singlet oxygen $\left({ }^{1} \mathrm{O}_{2}\right)$ is transformed into a hydrophilic sulfoxide derivative facilitating the disassembly of photosensitizer-delivery particles during the PDT process. A peripherally substituted carboxy-Zn(II)-phthalocyanine derivative (TT1) bearing a carboxyl group directly linked to the Pc-ring, and presenting an absorption maximum around $680 \mathrm{~nm}$, was selected as PS which simultaneously acted as a photooxidation catalyst. A TT1-ELP $\left[\mathrm{M}_{1} \mathrm{~V}_{3}-40\right]$ conjugate was prepared from ELP $\left[\mathrm{M}_{1} \mathrm{~V}_{3}-40\right]$ modified with an alkyne group at the $N$-terminal chain end, and from TT1-amide-C3-azide by copper(I)-catalyzed alkyne-azide cycloaddition (CuAAC) reaction. This innovative model photooxidation sensitive PS delivery technology offers promising attributes in terms of temperature-controlled particle formation and oxidation-triggered release, narrow molar mass distribution, reproducibility, scalability, non-immunogenicity, biocompatibility and biodegradability for pharmaceutical applications in an effort to improve the clinical effectiveness of PDT treatments.

KEYWORDS: Elastin-like polypeptide, photodynamic therapy, carboxy $\mathrm{Zn}(\mathrm{II})-$ phthalocyanine, photooxidation, stimuli-responsive self-assembly, bioconjugate 


\section{INTRODUCTION}

Photodynamic therapy (PDT) is an attractive non-invasive cancer treatment alternative with higher selectivity and lower side effects as compared to conventional methods like surgery, chemotherapy, and radiotherapy. ${ }^{1,2}$ The main components of PDT, namely a photosensitizer (PS), light, and oxygen, are non-toxic individually, while locally generating highly toxic reactive oxygen species (ROS) when used in combination via energy or electron transfer from the excited triplet state of the PS to nearby molecular oxygen. ${ }^{3}$ This can imply the selective activation of non-toxic photosensitizers accumulated at tumor sites with NIR light $(600-800 \mathrm{~nm}))^{4,5}$ During photo-irradiation, generated ROS cause multiple oxidative damages to the surrounding microenvironment impairing malignant cells' metabolic function leading to apoptosis and/or necrosis. ${ }^{6,7}$ Small scale inflammations, occurring after PDT anti-cancer treatment, have also been shown to activate the natural immune system against malignant cells, resulting in the complete destruction of the tumor and limiting the risk of tumor recovery. ${ }^{8}$ Together with low dark toxicity, the success of PDT mainly relies on the photophysical properties of the selected PS (extinction coefficient $(\varepsilon)$, singlet oxygen $\left({ }^{1} \mathrm{O}_{2}\right)$ generation quantum yield $\left(\Phi_{\Delta}\right)$, etc. $)$ and its effective accumulation at the tumor site. ${ }^{1,9-11}$ Phthalocyanine (Pc) derivatives, considered as second generation PS, are synthetic formal derivatives of porphyrins, with superior photophysical properties and high chemical versatility. ${ }^{10}$ Several Pc-based photosensitisers (Photosens, Photocyanine, Pc 4, IRDye®700DX) have been approved for clinical use or are in advanced stages of clinical trials. ${ }^{12,13}$ Further development of these phototherapeutic agents, both at the molecular level and as nanometer-sized formulations, is currently of strong interest. Pc derivatives are composed of four pyrrole subunits each one fused with an additional benzo ring and linked via nitrogen atoms. Extended conjugation and lone electron pairs on nitrogen atoms significantly increase electron density of the Pc backbone causing a red-shifting of the absorption wavelength and increasing the absorption coefficient, which are two essential parameters for effective PDT performance in complex biological media. ${ }^{11} \mathrm{Pc}$ metal ion chelates $\left(\mathrm{Zn}^{2+}, \mathrm{Al}^{3+}, \mathrm{Mg}^{2+}, \mathrm{Ru}^{2+}\right.$, etc. $)$ generally show efficient triplet state 
population, and consequently an increased ${ }^{1} \mathrm{O}_{2}$ generation yield. ${ }^{12,14,15}$ Due to the intrinsic hydrophobicity of Pcs, hydrophilic derivatives have been developed. Nevertheless and besides synthetic challenges, the uncontrolled aggregation tendency of Pc backbones combined with their low molar mass leads to uncontrolled biodistribution of this class of PS in the body. In this context, several studies have shown that macromolecular conjugates or nanocarriers of PSs improve their biodistribution, bioavailability and therapeutic outcome by increasing their solubility and plasma half-life, and avoiding fast renal clearance. ${ }^{16-18} \mathrm{~A}$ wide variety of synthetic and natural biocompatible polymers have been developed for nanomedicine applications, especially for the design of complex drug delivery vehicles. ${ }^{17}$ Among these, recombinant elastin-like polypeptides (ELPs) have attracted significant interest for drug delivery and tissue engineering applications due to their biocompatibility, biodegradability, low immunogenicity and stimuli-responsive properties. ${ }^{19,20}$ ELPs are artificial protein polymers derived from the hydrophobic domain of tropoelastin, the soluble precursor of elastin, and consists in repetitive sequences of [-Val-Pro-Gly-Xaa-Gly-] pentapeptides. ${ }^{21}$ Their inverse phase transition behavior provides a unique opportunity to engineer sophisticated stimuli-responsive delivery systems. ${ }^{20,22-24}$ Indeed, ELPs present lower critical solution temperature (LCST) phase behavior: below their critical aggregation temperature at a given concentration (cloud point, noted as $T_{\mathrm{CP}}$ ), ELP chains are soluble and mostly intrinsically disordered, while hydrophobically collapsing above the $T_{\mathrm{CP}}$. Our group has in particular developed chemoselectively modifiable recombinant ELP scaffolds for easy tuning of their thermal responsiveness by chemical modification. ${ }^{22,25-27}$ In particular, we have engineered methionine-containing ELP scaffolds that can be chemoselectively modified at the side chain of each methionine residue to tune their physico-chemical properties or to introduce specific functionalities..$^{25,26,28-30}$ Due to its sensitivity to oxidation, the thioether group of methionine can also be readily oxidized into sulfoxide, turning a hydrophobic methionine-containing ELP with low $T_{\mathrm{CP}}$ into a hydrophilic sulfoxide derivative with high $T_{\mathrm{CP} .}{ }^{22}$ In the present work, we show that this characteristic property can be used to 
develop smart temperature and singlet oxygen responsive ELP-PS conjugates as illustrated in Figure 1.

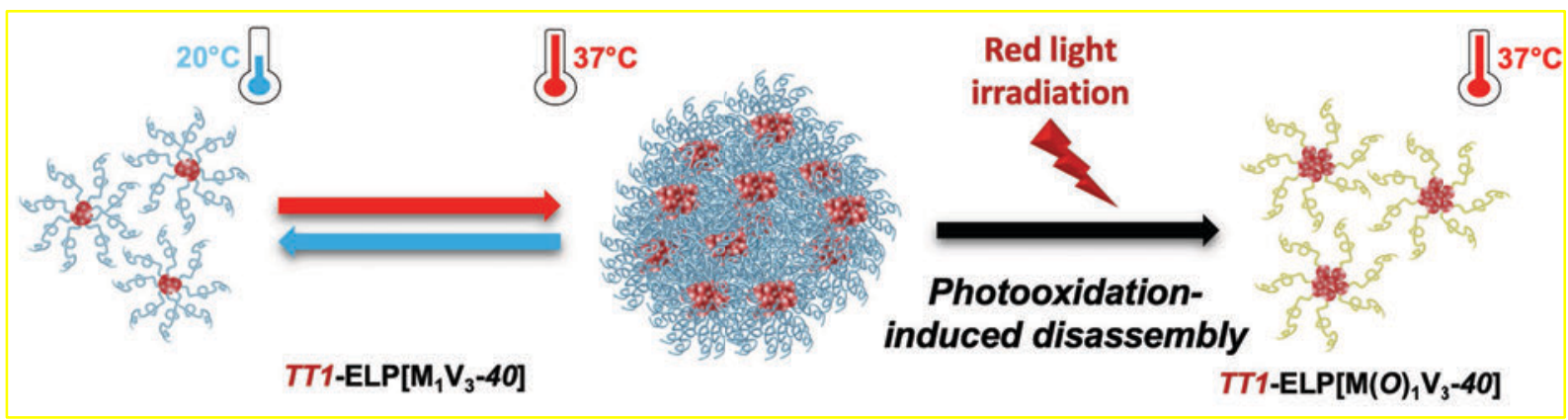

Figure 1. Proposed mechanism of assembly of TT1-ELP[M $\left.\mathrm{M}_{1} \mathrm{~V}_{3}-40\right]$ conjugates into micellar coacervates at $37^{\circ} \mathrm{C}$ and disassembly into individual micelles upon photoirradiation.

Towards this goal, an ELP containing 40 (VPGXG) pentapeptide repeats with $\mathrm{X}=\mathrm{M} / \mathrm{V}$ (1:3) (denoted ELP $\left[\mathrm{M}_{1} \mathrm{~V}_{3}-40\right]$ ) was conjugated at the $N$-terminal chain end with a $\mathrm{Zn}(\mathrm{II})$ phthalocyanine PS (noted TT1). Upon specific photo-irradiation of the PS, ELP $\left[M_{1} \mathrm{~V}_{3^{-}}\right.$ $40]$ was found to be oxidized into its sulfoxide derivative $\operatorname{ELP}\left[\mathrm{M}(O)_{1} \mathrm{~V}_{3}-40\right]$ turning the hydrophobic TT1-ELP $\left[\mathrm{M}_{1} \mathrm{~V}_{3}-40\right]$ conjugate, which self-assembled into large micellar coacervates at physiological body temperature, into an amphiphilic TT1-ELP $\left[\mathrm{M}(O)_{1} \mathrm{~V}_{3^{-}}\right.$ 40] conjugate self-assembled into small micelles, that shall diffuse more easily in dense tumors allowing for a second photo-irradiation and even more efficient PDT.

\section{RESULTS AND DISCUSSION}

The ELP used in the present work, namely ELP $\left[\mathrm{M}_{1} \mathrm{~V}_{3}-40\right]$ with the exact protein sequence $\mathrm{MW}\left[(\mathrm{VPGVG})(\mathrm{VPGMG})(\mathrm{VPGVG})_{2}\right]_{10}$ was produced recombinantly in Escherichia coli (E. coli) bacteria following previously reported procedures. ${ }^{22,25} \mathrm{~A}$ peripherally substituted carboxy-Zn(II)-phthalocyanine derivative (TT1) was selected as photosensitizer due to its outstanding photo-physical properties. ${ }^{31-33}$ It has a carboxyl group directly linked to the Pc-ring and exhibits an excellent absorption coefficient around $680 \mathrm{~nm}\left(\varepsilon \sim 10^{5} \mathrm{M}^{-1} \cdot \mathrm{cm}^{-1}\right)$, whereas its UV-Vis spectrum offers a broad therapeutic optical window. Such a design of photosensitizers in the near-infrared (NIR) 
window (650-950 nm), also referred as the "therapeutic window", is specifically relevant for biomedical applications as the absorption by other chromophores and/or by the tissues is minimized, allowing for a most effective laser therapy. The singlet oxygen quantum yield of TT1 measured in DMSO mounts up to $\Phi_{\Delta}=0.72$. The presence of tertbutyl groups not only minimizes the formation of molecular aggregates, ${ }^{31}$ but also increases the solubility of TT1 in organic solvents. TT1 is actually constituted of a mixture of eight regioisomers, in equal proportions. TT1 was synthesized according to a previously described procedure. $^{31}$ The compound was then reacted with 3azidopropylamine, COMU® (\{[(Z)-(1-Cyano-2-ethoxy-2-oxoethylidene)amino]oxy $\}$ $N, N$-dimethyl(morpholin-4-yl)methaniminium hexafluorophosphate), and diisopropylethylamine in DMF to yield TT1-amide-C3-azide in 75\% yield. (Scheme S1, Figure S1-3)

The TT1-ELP $\left[\mathrm{M}_{1} \mathrm{~V}_{3}-40\right]$ conjugate was then prepared from ELP[M $\left.\mathrm{M}_{1} \mathrm{~V}_{3}-40\right]$ modified with an alkyne group at the $N$-terminal chain end following a protocol established by our group, ${ }^{27}$ and from TT1-amide-C3-azide by copper(I)-catalyzed alkyne-azide cycloaddition (CuAAC) reaction in DMSO. (Scheme 1) The reaction mixture was extensively degassed via freeze-thaw cycles under vacuum to prevent oxidation of methionine residues. Excess copper was removed by treatment of the reaction mixture with Cuprisorb® beads followed by filtration, and the reaction product was precipitated with diethyl ether. The precipitate was dissolved in ultrapure water and further purified by inverse transition cycling (ITC) ${ }^{34}$ yielding the pure TT1-ELP $\left[\mathrm{M}_{1} \mathrm{~V}_{3}-40\right.$ ] conjugate, as assessed by different analytical techniques, in $80 \%$ overall yield. Quantitative modification at the ELP chain end and complete removal of excess TT1 used for the reaction were confirmed by MALDI MS, SDS-PAGE and SEC analyses. (Figure 2AC) MALDI MS analysis of TT1-ELP[M $\left.\mathrm{M}_{1} \mathrm{~V}_{3}-40\right]$ showed a single peak at 18,033.5 in perfect agreement with the theoretical molar mass. (Figure $2 \mathbf{A}$ and Table 1) 


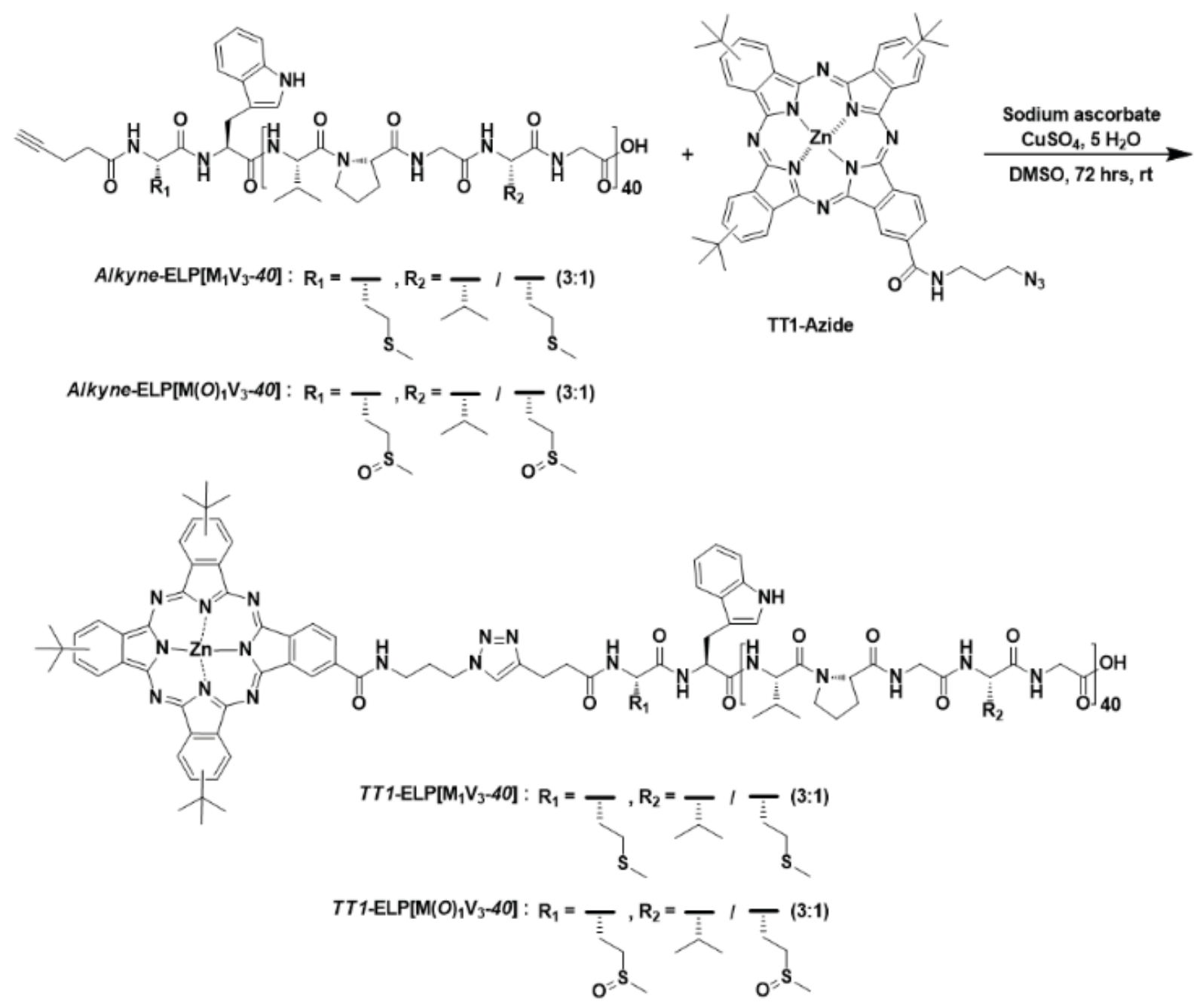

Scheme 1. Synthetic scheme to access TT1-ELP $\left[\mathrm{M}_{1} \mathrm{~V}_{3}-40\right]$ and the reference compound TT1$\operatorname{ELP}\left[\mathrm{M}(O)_{1} \mathrm{~V}_{3}-40\right]$.

SDS-PAGE analysis showed the successful removal of excess TT1 used for the reaction. (Figure 2B and Figure S4) The SEC chromatogram of TT1-ELP[M $\left.\mathrm{M}_{3}-40\right]$ (RI detection) revealed a monomodal peak distribution. (Figure 2C) The presence of a small shoulder at shorter retention times is attributed to aggregates of TT1-ELP $\left[\mathrm{M}_{1} \mathrm{~V}_{3}-40\right]$ due to $\pi-\pi$ stacking of the TT1 planar backbone. Absorption at $607 \mathrm{~nm}$ also indicated the successful attachment of TT1 to the ELP chain end. (Figure 2C) 

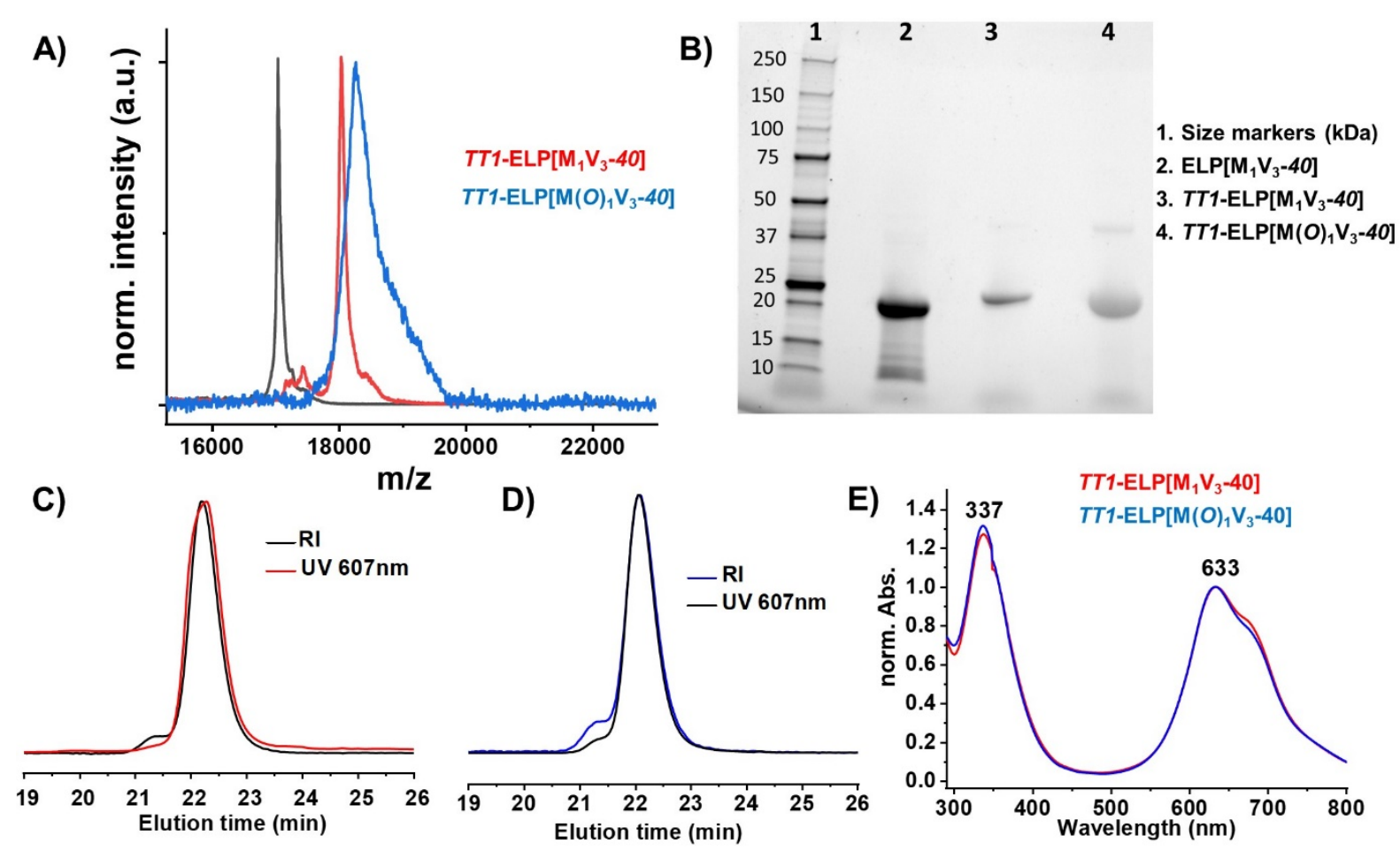

Figure 2. Characterization of TT1-ELP $\left[\mathrm{M}_{1} \mathrm{~V}_{3}-40\right]$ and TT1-ELP $\left[\mathrm{M}(O)_{1} \mathrm{~V}_{3}-40\right]$ conjugates. (A) Superimposed MALDI mass spectra of TT1-ELP[M $\left.\mathrm{M}_{1} \mathrm{~V}_{3}-40\right]$ and TT1$\operatorname{ELP}\left[\mathrm{M}(O)_{1} \mathrm{~V}_{3}-40\right]$. The spectrum of ELP $\left[\mathrm{M}_{1} \mathrm{~V}_{3}-40\right]$ is provided for comparison (black trace). (B) SDS-PAGE analysis. (C) Size exclusion chromatogram of TT1-ELP $\left[\mathrm{M}_{1} \mathrm{~V}_{3}\right.$ 40] in DMSO (red trace: RI detection; black trace: UV detection at $607 \mathrm{~nm}$ ). (D) Size exclusion chromatogram of TT1-ELP $\left[\mathrm{M}(O)_{1} \mathrm{~V}_{3}-40\right]$ in DMSO (blue trace: RI detection; black trace: UV detection at $607 \mathrm{~nm}$ ). E) Overlapped absorption spectra of TT1ELP $\left[\mathrm{M}_{1} \mathrm{~V}_{3}-40\right]$ (red trace) and TT1-ELP $\left[\mathrm{M}(O)_{1} \mathrm{~V}_{3}-40\right]$ (blue trace) in PBS buffer at 25 ${ }^{\circ} \mathrm{C}$.

${ }^{1} \mathrm{H}$ NMR spectroscopy was performed at $5{ }^{\circ} \mathrm{C}$ to insure full solubility of TT1-ELP $\left[\mathrm{M}_{1} \mathrm{~V}_{3^{-}}\right.$ 40]. A slight oxidation of methionine residues $(8 \%$, i.e. less than one methionine over a total of 11) was observed which may have been caused by short term light exposure during sample preparation or during analysis. (Figure S5)

Methionine residue oxidation in proteins is a natural mechanism used in mammalian cells to deactivate the small amounts of ROS generated and accumulated in the body. ${ }^{35,36}$ These so called antioxidant proteins can be recovered via MSR enzymes (methionine sulfoxide reductases) by reducing the sulfoxide to repair the original methionine. ${ }^{36}$ Because in this study the designed ELP $\left[\mathrm{M}_{1} \mathrm{~V}_{3}-40\right]$ contains periodically spaced 
methionine residues prone to oxidation, and therefore highly sensitive to reactive oxygen species, we hypothesized that photo-irradiation of TT1-ELP $\left[\mathrm{M}_{1} \mathrm{~V}_{3}-40\right]$ would oxidize the methionine thioether groups (11 total in the sequence of ELP $\left[M_{1} V_{3}-40\right]$ ), increase the $T_{\mathrm{CP}}$ of the conjugate due to increased polarity, ${ }^{22}$ and possibly trigger the disassembly of micellar coacervates formed at physiological body temperature.

To verify this hypothesis, we have synthesized in parallel the reference compound noted $T T 1-\left[\mathrm{M}(O)_{1} \mathrm{~V}_{3}-40\right]$ in which all methionine residues are oxidized into sulfoxide form. The latter was obtained from the sulfoxide derivative $\operatorname{ELP}\left[\mathrm{M}(O)_{1} \mathrm{~V}_{3^{-}}-40\right]$ functionalized with an alkyne group at the $N$-terminal chain end, and from TT1-amide-C3-azide by CuAAC reaction in DMSO, and purified following similar procedures to those used for TT1-ELP $\left[\mathrm{M}_{1} \mathrm{~V}_{3}-40\right]$. (Scheme 1) ELP $\left[\mathrm{M}(O)_{1} \mathrm{~V}_{3}-40\right]$ was obtained by oxidation of the pristine ELP $\left[\mathrm{M}_{1} \mathrm{~V}_{3}-40\right]$ with hydrogen peroxide $\left(\mathrm{H}_{2} \mathrm{O}_{2}\right)$ following a protocol established by our group. ${ }^{22}$ (Figures S6-7) The quantitative oxidation of ELP $\left[\mathrm{M}_{1} \mathrm{~V}_{3}-40\right]$ was monitored by ${ }^{1} \mathrm{H}$ NMR (Figure S6) as well as the complete functionalization of the $\mathrm{N}$ terminal chain end. (Scheme S2 and Figure S8) TT1-amide-C3-azide conjugation to Alkyne-ELP $\left[\mathrm{M}(O)_{1} \mathrm{~V}_{3}-40\right]$ was confirmed by MALDI MS, SDS-PAGE, SEC, UV-Vis spectroscopy, and ${ }^{1} \mathrm{H}$ NMR analyses. (Figure 2A, B, D, E and Figure S9) MALDI MS analysis showed a shift of $1,174 \mathrm{Da}$ between the monocharged species, $[\mathrm{M}+\mathrm{H}]^{+}$, of ELP $\left[\mathrm{M}_{1} \mathrm{~V}_{3}-40\right]$ and TT1-ELP $\left[\mathrm{M}(O)_{1} \mathrm{~V}_{3}-40\right]$ in good agreement with the theoretical value $(1,177 \mathrm{Da})$. (Figure $2 \mathrm{~A}$ and Table 1) The SEC chromatogram of TT1-ELP[M $(O)_{1} \mathrm{~V}_{3^{-}}$ 40] (RI detection) showed a narrow monomodal peak distribution which overlapped with the UV detector signal at $607 \mathrm{~nm}$ indicating successful conjugation of TT1. (Figure 2D)

Table 1. Characteristics of ELP derivatives synthesized.

\begin{tabular}{|c|c|c|c|c|c|}
\hline \multirow[b]{2}{*}{ Compound notation } & \multirow{2}{*}{$\begin{array}{c}\mathrm{MW}^{\text {theo }} \\
\text { (Da) }\end{array}$} & \multirow{2}{*}{$\begin{array}{c}{[\mathrm{M}+\mathrm{H}]^{+}} \\
\mathrm{MALDI} \\
\mathrm{MS} \\
(\mathrm{Da}) \\
\end{array}$} & \multirow{2}{*}{$\begin{array}{c}\lambda_{\max }(\mathrm{nm}) \\
\text { in PBS }\end{array}$} & \multicolumn{2}{|c|}{$\mathrm{SEC}$ in DMSO } \\
\hline & & & & $\begin{array}{l}\mathrm{Mn} \\
(\mathrm{Da})\end{array}$ & $Đ$ \\
\hline $\mathrm{ELP}\left[\mathrm{M}_{1} \mathrm{~V}_{3}-40\right]$ & $17,035.4$ & $17,039.6$ & & 17,610 & 1.087 \\
\hline$T T 1-\mathrm{ELP}\left[\mathrm{M}_{1} \mathrm{~V}_{3}-40\right]$ & $18,032.9$ & $18,033.5$ & $337 \& 633$ & 20,120 & 1.129 \\
\hline $\operatorname{ELP}\left[\mathrm{M}(O)_{1} \mathrm{~V}_{3}-40\right]$ & $17,211.4$ & n.d. & & 19,841 & 1.177 \\
\hline
\end{tabular}


n.d. not determined

$T T 1-\operatorname{ELP}\left[\mathrm{M}(O)_{1} \mathrm{~V}_{3}-40\right] \quad 18,212.7 \quad 18,213.79 \quad 337 \& 633 \quad 20,710 \quad 1.239$

The thermo-responsive character of ELP $\left[\mathrm{M}_{1} \mathrm{~V}_{3}-40\right]$, before and after TT1 conjugation, was measured by turbidity assays in phosphate buffer (PBS, pH 7.4) following the absorbance at 600 and $500 \mathrm{~nm}$, respectively, over a temperature range from 10 to $65^{\circ} \mathrm{C}$. Measurements were performed at three concentrations $(10,20$ and $30 \mu \mathrm{M})$ at which TT1ELP $\left[\mathrm{M}_{1} \mathrm{~V}_{3}-40\right]$ is fully soluble at $10{ }^{\circ} \mathrm{C}$. At these concentrations, the transition temperature $\left(T_{\mathrm{CP}}\right)$ of the pristine $\operatorname{ELP}\left[\mathrm{M}_{1} \mathrm{~V}_{3}-40\right]$ was in the range of $35-38{ }^{\circ} \mathrm{C}$, close to physiological body temperature which is relevant with literature results for short chain length ELPs, ${ }^{37}$ and in full concordance with our previous studies. ${ }^{22}$ (Table 2) After conjugation of TT1, the $T_{\mathrm{CP}}$ was found to drop by approximately $10^{\circ} \mathrm{C}$, the $T_{\mathrm{CP}}$ of $T T 1$ ELP $\left[\mathrm{M}_{1} \mathrm{~V}_{3}-40\right]$ ranging from $29^{\circ} \mathrm{C}$ at $10 \mu \mathrm{M}$ to $27^{\circ} \mathrm{C}$ at $30 \mu \mathrm{M}$. (Table 2, Figure S10A)

Table 2. Summary of the transition temperature $\left(T_{C P}\right)$ of the different ELP conjugates.

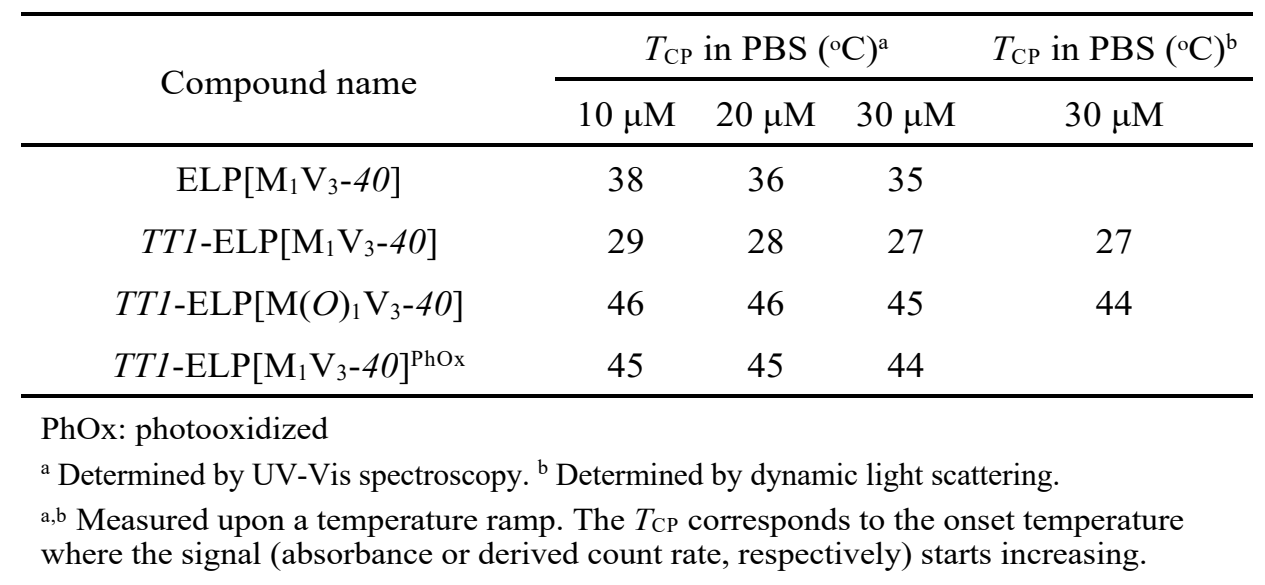

This was expected due to the strong hydrophobic character of TT1. The insertion of a hydrophobic molecular domain increases intra- and intermolecular hydrophobic interactions in the ELP backbones. ${ }^{38}$ In addition, dynamic light scattering evidenced the formation of very small micelles with a hydrodynamic diameter $D_{H} \sim 31 \pm 2 \mathrm{~nm}$ below $T_{\mathrm{CP}}$ of TT1-ELP $\left[\mathrm{M}_{1} \mathrm{~V}_{3}-40\right]$ as a consequence of TT1 intermolecular hydrophobic interactions (Figure S11). This self-assembly mechanism, that locally increases the ELP concentration, also explains the lower $T_{\mathrm{CP}}$. Above the $T_{\mathrm{CP}}$ of $T T 1-\mathrm{ELP}\left[\mathrm{M}_{1} \mathrm{~V}_{3}-40\right]$ around 
$27{ }^{\circ} \mathrm{C}$, larger micellar coacervates of $2.7 \mu \mathrm{m}$ could be observed, suggesting that TT1ELP $\left[\mathrm{M}_{1} \mathrm{~V}_{3}-40\right]$ would be aggregated when used in vivo. In clinical application, these smart particles could be disassembled upon local cryothermia ${ }^{39}$ at the tumor to let the small micelles of TT1-ELP $\left[\mathrm{M}_{1} \mathrm{~V}_{3}-40\right]$ diffuse deeper into the tumor mass before applying the PDT treatment.

Interestingly, the disassembly of $T T 1-\mathrm{ELP}\left[\mathrm{M}_{1} \mathrm{~V}_{3}-40\right]$ coacervates could also be triggered by oxidation of methionine residues by ${ }^{1} \mathrm{O}_{2}$ generated upon TT1 activation by NIR light. Indeed, the thermo-responsive behavior of the chemically oxidized conjugate TT1$\operatorname{ELP}\left[\mathrm{M}(O)_{1} \mathrm{~V}_{3}-40\right]$ measured in similar conditions to those used for TT1-ELP $\left[\mathrm{M}_{1} \mathrm{~V}_{3}-40\right]$ (PBS, pH 7.4) showed a huge jump $\left(\sim 17{ }^{\circ} \mathrm{C}\right)$ in $T_{\mathrm{CP}}$ as compared to the non-oxidized conjugate. (Table 2, Figure 4A, B and Figure S10C) With a $T_{\mathrm{CP}}$ of ca. $45^{\circ} \mathrm{C}$, well above body temperature, the oxidized conjugate TT1-ELP $\left[\mathrm{M}(O)_{1} \mathrm{~V}_{3}-4 O\right]$ coacervates shall therefore be destabilized at $37^{\circ} \mathrm{C}$.

As a proof of concept, a solution of TT1-ELP $\left[\mathrm{M}_{1} \mathrm{~V}_{3}-40\right]$ in $\mathrm{D}_{2} \mathrm{O}$ was therefore subjected to irradiation with a red-light emitting diode (LED, 630-640 nm) and ${ }^{1} \mathrm{H}$ NMR spectroscopy used to follow the selective oxidation of methionine residues. The formation of sulfoxide during the red emitting LED irradiation over 5, 10, 15, 20 and 30 minutes was monitored by the shift of the resonance peak at $2.1 \mathrm{ppm}$ attributed to the protons of the methyl group adjacent to the sulfur in the thioether form $\left(-\mathrm{SCH}_{3}\right)$ to 2.6 ppm in the sulfoxide form $\left(-\mathrm{S}(\mathrm{O}) \mathrm{CH}_{3}\right)$. (Figure 3A) Approximately 50\% oxidation was observed in $5 \mathrm{~min}$, while $30 \mathrm{~min}$ irradiation caused complete oxidation of the 11 methionine residues of the ELP. We also noticed an increased spectral resolution of ${ }^{1} \mathrm{H}$ NMR analyses performed at room temperature during the photooxidation process as a result of higher solubility of the conjugate formed noted TT1-ELP $\left[\mathrm{M}_{1} \mathrm{~V}_{3}-40\right]^{\text {PhOx}}$. The overlapped SEC chromatograms of TT1-ELP $\left[\mathrm{M}_{1} \mathrm{~V}_{3^{-}}-40\right]^{\mathrm{PhOx}}$ showed narrow monomodal peak distribution confirming the selectivity of the oxidation process without any traces 
of crosslinking or degradation in the backbone. (Figure 3B) Increased dimer population displayed in SEC and also observed in SDS-PAGE gel (Figure 3C), is probably due to the strong hydrophobic interactions between TT1 chain ends.
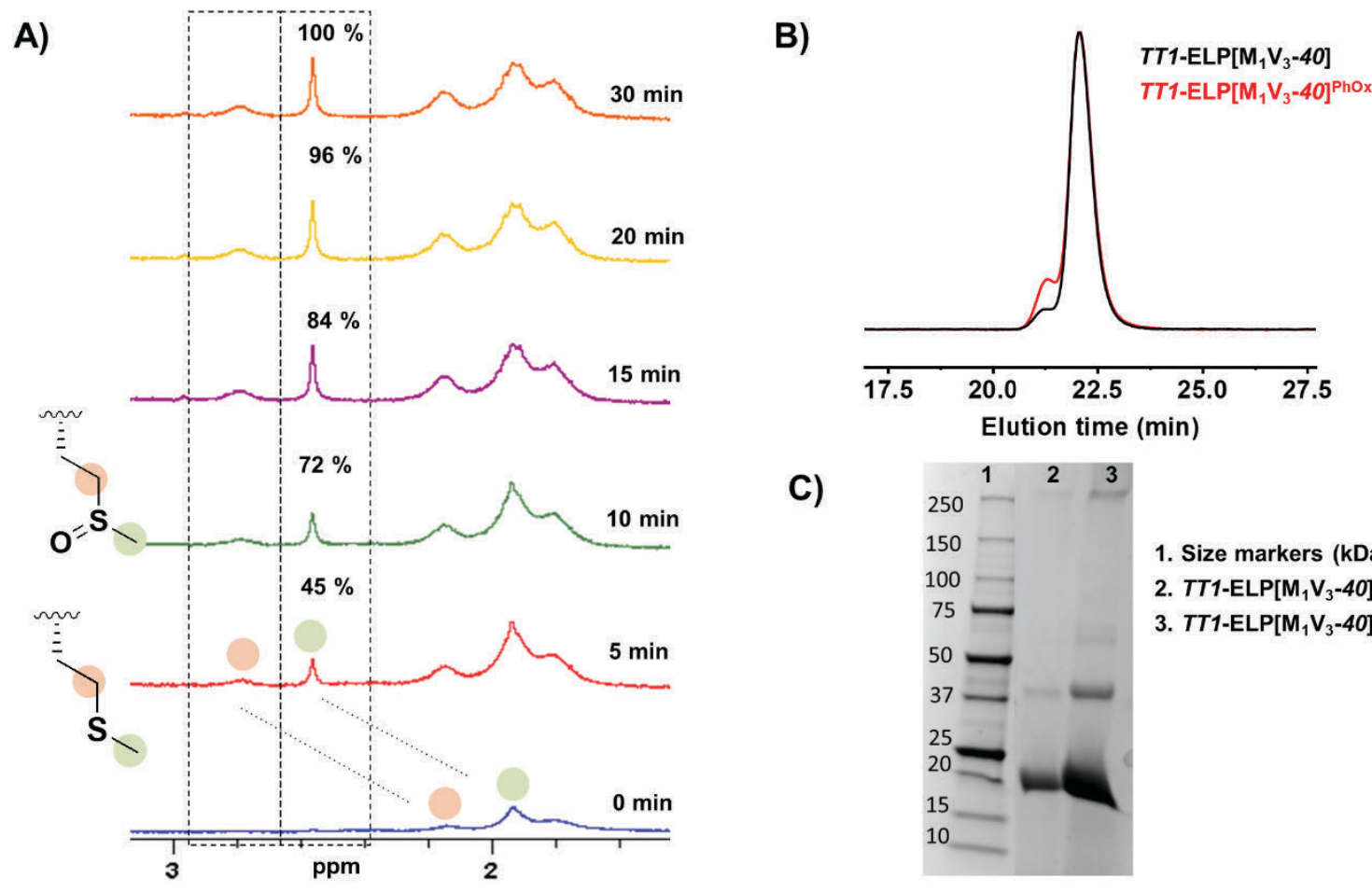

C)

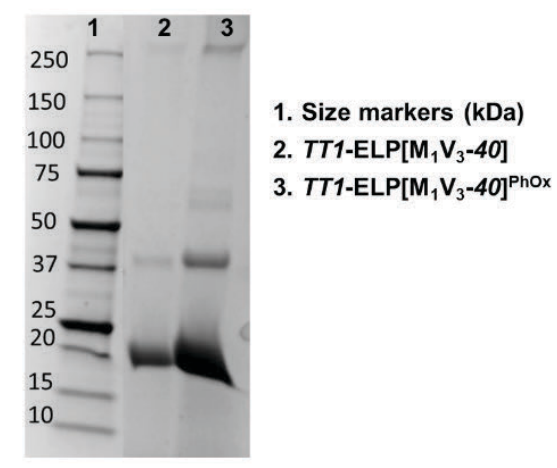

Figure 3. (A) Stacked ${ }^{1} \mathrm{H}$ NMR spectra of TTl-ELP $\left[\mathrm{M}_{1} \mathrm{~V}_{3}-40\right]$ after photoirradiation during 5, 10, 15, 20, and 30 minutes $\left(\mathrm{D}_{2} \mathrm{O}\right.$, room temperature, $\left.200 \mathrm{MHz}\right)$. (B) SEC chromatograms in DMSO of TT1-ELP $\left[\mathrm{M}_{1} \mathrm{~V}_{3}-40\right]$ before (black curve, RI detection) and after photoirradiation (red curve, RI detection). (C) SDS-PAGE analysis (coomassie blue stain).

The thermo-responsive character of the photo-oxidized conjugate, TT1-ELP $\left[\mathrm{M}_{1} \mathrm{~V}_{3^{-}}\right.$ $40]^{\mathrm{PhOx}}$, was also measured by turbidimetry and compared to the one of the starting TT1ELP $\left[\mathrm{M}_{1} \mathrm{~V}_{3}-40\right]$ conjugate and of the reference compound TTl-ELP $\left[\mathrm{M}(O)_{1} \mathrm{~V}_{3}-40\right]$. The $T_{\mathrm{CP}}$ at $30 \mu \mathrm{M}$ in PBS was shifted from $27{ }^{\circ} \mathrm{C}$ for TT1-ELP $\left[\mathrm{M}_{1} \mathrm{~V}_{3^{-}}-40\right]$ to $44{ }^{\circ} \mathrm{C}$ (Figure 4A, $B$ and Figure S10B) in perfect agreement with the value obtained for the chemically synthesized sulfoxide version TT1-ELP[M(O) $\left.)_{1} \mathrm{~V}_{3}-40\right]$. (Table 2 and Figure S10C) One would expect a drastic change in physicochemical properties of the ELP backbone resulting from the sulfoxide formation, with a shift of the phase transition temperature of the conjugate and a destabilization and disassembly of the coacervates observed at body temperature. 

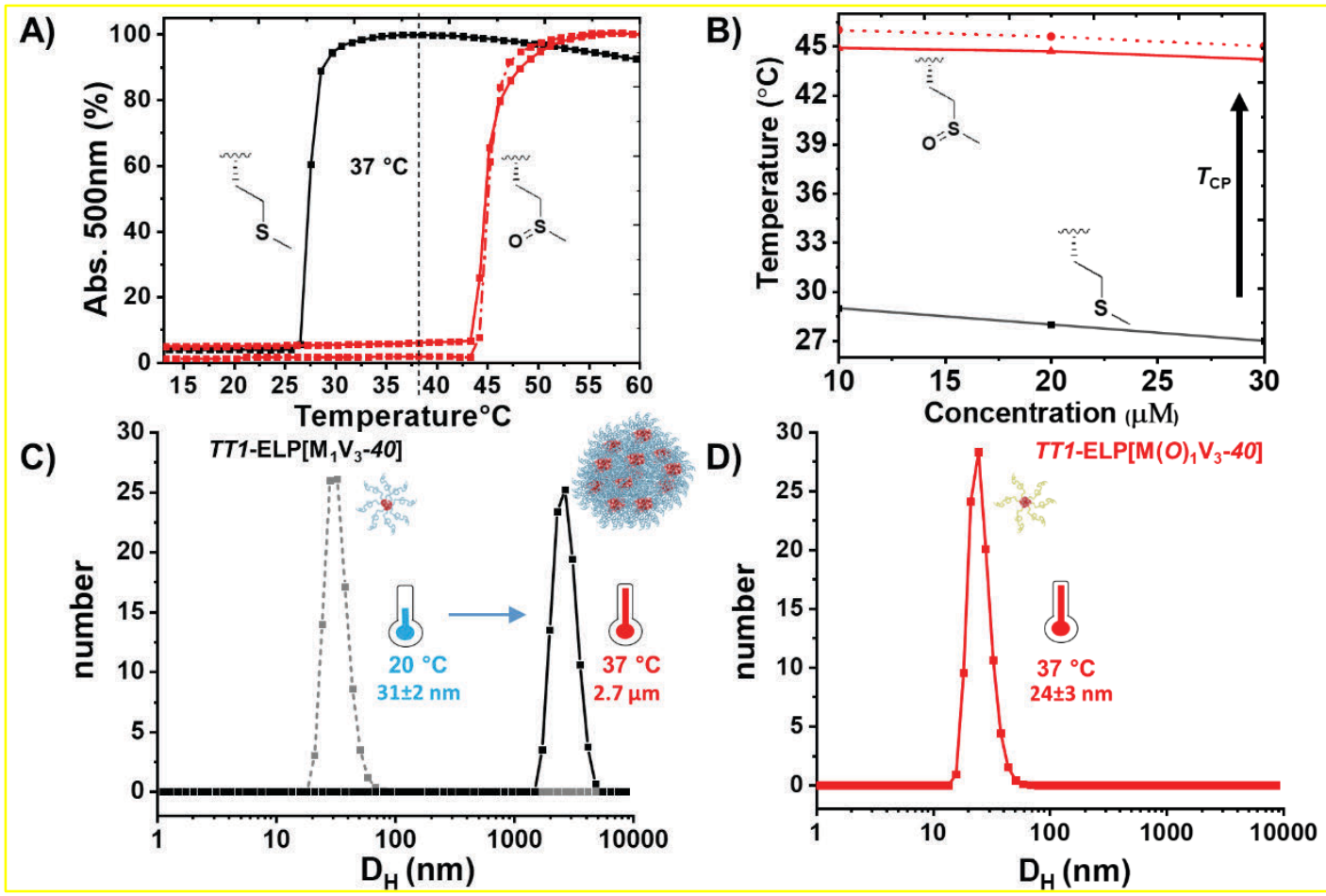

Figure 4. A) Normalized relative absorbance at $500 \mathrm{~nm}$ of $30 \mu \mathrm{M}$ solution of TT1-ELP[M $\mathrm{M}_{1} \mathrm{~V}_{3^{-}}$ 40] (black trace), TT1-ELP $\left[\mathrm{M}_{1} \mathrm{~V}_{3}-40\right]^{\text {PhOx }}$ (red trace) and TT1-ELPM $\left.(O)_{1} \mathrm{~V}_{3}-40\right]$ (red dots) conjugates in PBS as a function of temperature. B) Transition temperature $\left(T_{\mathrm{CP}}\right)$ versus molar concentration of TT1-ELP $\left[\mathrm{M}_{1} \mathrm{~V}_{3}-40\right]$ (black), TT1-ELP $\left[\mathrm{M}_{1} \mathrm{~V}_{3}-40\right]^{\text {PhOx }}$ (red) and TT1$\operatorname{ELP}\left[\mathrm{M}(O)_{1} \mathrm{~V}_{3}-40\right]$ (red dots). C) Size distribution (in number) of TT1-ELP $\left[\mathrm{M}_{1} \mathrm{~V}_{3}-40\right]$ at $20{ }^{\circ} \mathrm{C}$ and $37{ }^{\circ} \mathrm{C}(30 \mu \mathrm{M}$ concentration in PBS). D) Size distribution (in number) of TT1$\left.\operatorname{ELPM}(O)_{1} \mathrm{~V}_{3}-40\right]$ at $37^{\circ} \mathrm{C}(30 \mu \mathrm{M}$ concentration in PBS $)$.

In order to mimic the self-assembly and photooxidation-triggered disassembly profile of TT1-ELP $\left[\mathrm{M}_{1} \mathrm{~V}_{3}-40\right]$, dynamic light scattering (DLS) measurements were performed in physiological conditions (PBS pH 7.4 at $37{ }^{\circ} \mathrm{C}$ ) (Figure 4C). Due to the tendency of TT1 to aggregate, ${ }^{31,33}$ upon direct dissolution of TT1-ELP $\left[\mathrm{M}_{1} \mathrm{~V}_{3}-40\right]$ in PBS at ambient temperature $\left(20^{\circ} \mathrm{C}\right)$, small micelles with a hydrodynamic diameter $D_{H} \sim 31 \pm 2 \mathrm{~nm}$ were observed. (Figure 4C) Temperature-controlled high-speed AFM imaging also confirmed the presence of the micelles even at $15{ }^{\circ} \mathrm{C}$. (Figure S12A) Nevertheless, the strong absorption of the laser light used in the liquid AFM equipment by self-assembled particles above $37{ }^{\circ} \mathrm{C}$ prevented from obtaining a clear topological image. (Figure 
S12B). Increase of the solution temperature to $37{ }^{\circ} \mathrm{C}$ resulted in the formation of large coacervates (ca. $2.7 \mu \mathrm{m}$ hydrodynamic diameter) in PBS (pH 7.4), while dropping the temperature back to $20{ }^{\circ} \mathrm{C}$ leads to the disassembly of these aggregates back to small micelles $\left(D_{H} \sim 31 \pm 2 \mathrm{~nm}\right)$. (Figure 4C) In contrast, DLS analysis of $T T 1-\operatorname{ELP}\left[\mathrm{M}(O)_{1} \mathrm{~V}_{3^{-}}\right.$ 40] at $37^{\circ} \mathrm{C}$ in PBS (pH 7.4) evidenced only the presence of small micelles $\left(D_{H} \sim 24 \pm 3\right.$ nm) with no larger coacervates. (Figure 4D)

We believe this experimental demonstration of the multi-responsive behavior of this PS delivery system to be potentially very interesting in terms of clinical applications. Indeed, one could expect that self-assembled TT1-ELP $\left[\mathrm{M}_{1} \mathrm{~V}_{3}-40\right]$ conjugates accumulated at the tumor site would disassemble upon local photoirradiation (PDT ${ }^{1}$ ) due to methionine residues oxidation and increase of $T_{\mathrm{CP}}$. Soluble photo-oxidized micellar conjugates would consequently diffuse deeper into the tumor tissue and improve the efficacy of a second photoirradiation $\left(\mathrm{PDT}^{2}\right)$ as illustrated in Figure 1. The reactivation of photosensitizers $\left(\mathrm{PDT}^{2}\right)$ may then cause considerable damage to the tumor mass and maximize therapeutic benefit.

Furthermore, therapeutic efficacy of PSs strongly depends on their optical and photophysical properties. Optical characterization of TT1-ELP conjugates at ambient temperature showed no difference in absorption maxima at PBS buffer $\left(\mathrm{pH} 7.4, \lambda_{\mathrm{abs}}=337\right.$ and $633 \mathrm{~nm}$ ). (Figures 2E) Owing to the conjugation to the polypeptide, aqueous environment with higher ionic strength and stacking of TT1 chain ends, the absorption peaks of the conjugates get broader and blue-shifted from $673 \mathrm{~nm}$ (TT1 in THF) to 633 $\mathrm{nm}$ (conjugate in PBS). The TT1 dimer/multimer formation in the unfavorable solvent (PBS buffer) also quenches the fluorescence property, nevertheless this has no remarkable effect on the singlet oxygen generation property. The comparison of the absorption spectrum of TT1-ELP $\left[\mathrm{M}_{1} \mathrm{~V}_{3}-40\right]^{\text {PhOx }}$ with the control compound TT1$\operatorname{ELP}\left[\mathrm{M}(O)_{1} \mathrm{~V}_{3}-40\right]$ in water revealed slight decrease in absorption band at $630 \mathrm{~nm}$ despite the long light exposure (30 min LED, $650 \mathrm{~nm}$ ) where the absorption at $339 \mathrm{~nm}$ remains 
unchanged, indicating the potential photostability of TT1 during long lasting phototherapies. (Figure S13)

\section{Conclusions}

Nature-inspired genetically engineered recombinant ELPs are remarkable smart polypeptides for biomedical applications owing to their controlled molecular weight, exquisite design, thermal responsiveness, biocompatibility and non-immunogenicity. ${ }^{40}$ In addition, the cost effective production in large scale with precise control on molecular composition makes them excellent drug delivery matrix polymers that can deliver and release a targeted drug (PS) in response to external stimuli. ${ }^{41,42}$ Here we experimentally demonstrated a new approach for the delivery of a photosensitizing molecule, namely a peripherally substituted carboxy-Zn(II)phthalocyanine (TT1), to be used in PDT cancer treatment by using Met's ROS scavenging property to trigger the disassociation of self-assembled micellar coacervates due to the emerging oxidized chain. To this end, we have prepared a TT1-ELP $\left[\mathrm{M}_{1} \mathrm{~V}_{3}-40\right]$ conjugate from recombinant ELP $\left[\mathrm{M}_{1} \mathrm{~V}_{3}-40\right]$ modified with an alkyne group at the $N$-terminal chain end, and from TT1 functionalized with an azido group. Unlike previously reported drug-ELP conjugates, ${ }^{19}$ such conjugates do not require additional treatment such as local hyperthermia to trigger in vivo dis-assembly. On the contrary, local disassembly can be promoted by a first PDT treatment that would allow micellar conjugates to diffuse deeper into the tumor tissue enabling a more efficient second PDT. We believe this strategy opens an interesting possibility to construct multi-responsive bioinspired delivery systems with externally controlled hydrophobic association and dissociation properties. Moreover, besides remarkable responsive properties, 
this model delivery system offers a quantitative control on PS concentration and prevents its uncontrolled accumulation and leakage before reaching the targeted site.

\section{MATERIALS AND METHODS}

\section{Materials}

The following reagents have been used as they were received: sodium chloride $(\mathrm{NaCl}, \mathrm{VWR}$, $100 \%)$, ammonium acetate $\left(\mathrm{C}_{2} \mathrm{H}_{3} \mathrm{O}_{2} \mathrm{NH}_{4}\right.$, Sigma-Aldrich, BioXtra 98\%), acetic acid glacial $\left(\mathrm{CH}_{3} \mathrm{CO}_{2} \mathrm{H}\right.$, Chem-Labs Limited), $N, N$-diisopropylethylamine (DIPEA, Sigma-Aldrich, 99\%), copper (II) sulfate pentahydrate $\left(\mathrm{Cu}_{2} \mathrm{SO}_{4} 5 \mathrm{H}_{2} \mathrm{O}\right.$, Acros Organics, $\left.98 \%\right)$, (+)-Sodium $L$-ascorbate $\left(\mathrm{C}_{6} \mathrm{H}_{7} \mathrm{NaO}_{6}\right.$, Sigma-Aldrich, 98\%), 9(10),16(17),23(24)-Tri-tert-butyl-2-carboxy-5,28:14,19diimino-7,12:21,26-dinitrilotetrabenzo[c,h,m,r][1,6,11,16]tetraazacycloeicosinato-(2)$\mathrm{N} 29, \mathrm{~N} 30, \mathrm{~N} 31, \mathrm{~N} 32$ zinc (II) (mixture of regioisomers) (TT1), 3-azidopropylamine $\left(\mathrm{C}_{3} \mathrm{H}_{8} \mathrm{~N}_{4}\right.$, TCI Europe, $>95 \%)$, $\mathrm{COMU} 囚\left(\mathrm{C}_{12} \mathrm{H}_{19} \mathrm{~F}_{6} \mathrm{~N}_{4} \mathrm{O}_{4} \mathrm{P}\right.$, Sigma-Aldrich, 97\%), Cuprisorb® (Seachem). The following solvents have been used without further purification: ethanol (EtOH, VWR chemicals, analytical grade, 100\%), dichloromethane (DCM, Sigma-Aldrich, analytical grade, 99.9\%), $N, N$ - dimethylformamide (DMF, Fluka, 99.8\%), acetonitrile (ACN, VWR chemicals, HPLC grade, 99.9\%), diethyl ether ( $\mathrm{Et}_{2} \mathrm{O}$, VWR chemicals, 97\%), dimethyl sulfoxide (DMSO, Sigma-Aldrich, 99,9\%), 1,4-dioxane (Carlo Erba, HPLC - Stabilized with BHT), n-hexane (Carlo Erba, for analysis, 99\%).

\section{Experimental procedures}

\section{Synthesis of TT1-amide-C3-azide}

COMU (16.8 mg, $0.039 \mathrm{mmol})$ was added to a mixture of TT1 (20 mg, $0.025 \mathrm{mmol})$, freshly distilled DIPEA $(5.3 \mu \mathrm{L})$ in dry DMF $(0.5 \mathrm{~mL})$ at room temperature under Ar atmosphere. Then, 3-azidopropylamine $(4.0 \mathrm{mg}, 0.04 \mathrm{mmol})$ was added dropwise. The reaction mixture was 
stirred for $24 \mathrm{~h}$. The mixture was diluted with DCM $(2 \mathrm{~mL})$ and extracted with $1 \mathrm{~N} \mathrm{HCl}(2 \times 5$ $\mathrm{mL}), 1 \mathrm{~N} \mathrm{NaHCO} 3(2 \times 5 \mathrm{~mL})$ and saturated $\mathrm{NaCl}(2 \times 5 \mathrm{~mL})$. DCM was then dried with $\mathrm{MgSO}_{4}$, the solvent was removed, and the crude was directly purified by flash column chromatography on silica gel (dioxane/n-hexane $=50: 50)$ to give $16.4 \mathrm{mg}$ of $1(75 \%)$ as a dark blue solid.

${ }^{1} \mathrm{H}-\mathrm{NMR}$ (300 MHz, DMSO-d6): $\delta 9.91$ (m, 1H), 9,55-9,30 (m, 8H), 8,71 (m,1H), 8,37 (m, 3H),3,63 (m, 2H), 2.07-2.02 (m, 2H), $1.78(\mathrm{~s}, 27 \mathrm{H}), 1.24(\mathrm{~m}, 2 \mathrm{H})$ ppm. HR-MS (MALDI-TOF, DCTB): Calc. for $\mathrm{C}_{48} \mathrm{H}_{46} \mathrm{~N}_{12} \mathrm{OZn}:[\mathrm{M}]^{+}: \mathrm{m} / \mathrm{z}$ : theoretical 870.3209, experimental 870.3204. UV/Vis: (THF): $\lambda_{\max }(\mathrm{nm})(\varepsilon)=673$ (4.70); 607 (4.68), 348 (4.08).

\section{General procedures for TT1-ELP conjugates syntheses}

Alkyne-ELP (1 equiv.) and TT1 (Zn(II)-phthalocyanine, 2 equiv.) were dissolved in dry DMSO (10 mg mL $\mathrm{mL}^{-1}$ ) and $\mathrm{CuSO}_{4} 5 \mathrm{H} 2 \mathrm{O}$ (1 equiv.) and sodium ascorbate (2 equiv.) were added and the solution was degassed by freeze-pump-thaw cycles. The solution left under stirring for $72 \mathrm{~h}$ at room temperature under $\mathrm{N}_{2}$ atmosphere. Excess copper was removed by Cuprisorb beads and subsequent filtration. The reaction solution was dialyzed (MWCO $3.5 \mathrm{kDa}$ ) against ultrapure water for $48 \mathrm{~h}$ and lyophilized. The final product was purified by inverse transition cycling (ITC) and lyophilized.

\section{General procedures of ITC purification for TT1-ELP conjugates}

The blue product was dissolved in $1 \mathrm{M} \mathrm{NaCl}$ solution $(5 \mathrm{~mL})$ and placed on a heating bath (40 $\left.{ }^{\circ} \mathrm{C}\right)$. Fluctuated conjugates were centrifuged during $10 \mathrm{~min}$ at $38{ }^{\circ} \mathrm{C}(3800 \mathrm{RPM}$ speed). The supernatant was discarded and the dark blue pellet was dissolved in cold water $(3 \mathrm{~mL})$. The solution was centrifuged for $30 \mathrm{~min}$ at $4{ }^{\circ} \mathrm{C}$ (3800 RPM speed) and the pellet was discarded. A few drops of $1 \mathrm{M} \mathrm{NaCl}$ solution was added into the supernatant and placed into the heating bath. Aggregated conjugates were centrifuged for $10 \mathrm{~min}$ at $38^{\circ} \mathrm{C}$ (3800 RPM speed). Finally the supernatant was discarded and the pellet was dissolved in cold ultrapure water and dialyzed 
against ultrapure water in a dialysis bag (cut-off MWCO $3.5 \mathrm{kDa}$ ) for $24 \mathrm{~h}$ to remove the excess salt. The solution was lyophilized to obtain pure blue conjugates.

\section{Analysis of TT1-ELP $\left[\mathrm{M}_{1} \mathrm{~V}_{3}-40\right]$}

Yield of pure conjugate is $16 \mathrm{mg}, 80 \%$.

${ }^{1} \mathrm{H}$ NMR (400 MHz, $\left.\mathrm{D}_{2} \mathrm{O}, 5{ }^{\circ} \mathrm{C}\right): \delta 4.38$ (br m, $11 \mathrm{H} \alpha \mathrm{CH} \mathrm{Me}$ ), 4.28-4.25 (m, 80H $\alpha \mathrm{CH}$ Val, Pro), 4.00-3.99 (d, 30H $\alpha \mathrm{CH}$ Val $_{\text {xaa) }}$ ), 3.80-3.77 (br m, 200H $\alpha \mathrm{CH} H_{2} \mathrm{Gly}, \delta \mathrm{CH}_{2}$ Pro), 3.54 (br , $40 \mathrm{H} \delta \mathrm{CH}_{2}$ Pro), 2.47-2.35 (br m, 22 $\gamma \gamma \mathrm{CH}_{2} \mathrm{Met}$ ), 2.16 (br m, $40 \mathrm{H} \beta \mathrm{CH}_{2}$ Pro), 1.93-1.80 (br m, $240 \mathrm{H} \beta \mathrm{CH}_{2}$ Met, $\beta \mathrm{CH}_{2}$ Pro, $\gamma \mathrm{CH}_{2}$ Pro, $\beta \mathrm{CH}_{2}$ Val, $\varepsilon \mathrm{CH}_{3} \mathrm{Met}$ ), 0.83-0.70 (m, $420 \mathrm{H}, \gamma \mathrm{CH}_{3}$ Val).

SEC (DMSO, LiBr $1 \mathrm{~g} \mathrm{~L}^{-1}$, standard: Dextran) $\mathrm{Mn}=20120 \mathrm{Da}, \mathrm{Mw} / \mathrm{Mn}=1.129$.

MALDI MS: theoretical MW $=18032.96 \mathrm{Da}$, experimental $[\mathrm{M}+\mathrm{H}]^{+}=18033.521 \mathrm{Da}$

UV absorption in water $\lambda_{\max }=337,633 \mathrm{~nm}$, no fluorescence.

\section{Analysis of TT1-ELP $\left[\mathrm{M}(O)_{1} \mathrm{~V}_{3}-40\right]$}

Yield of pure conjugate is $13 \mathrm{mg}, 58 \%$.

${ }^{1} \mathrm{H}$ NMR (400 MHz, $\left.\mathrm{D}_{2} \mathrm{O}, 5^{\circ} \mathrm{C}\right): \delta 4.38$ (br, $11 \mathrm{H} \alpha \mathrm{CH} \mathrm{Me}$ ), 4.25-4.26 (br, $80 \mathrm{H} \alpha \mathrm{CH}$ Val, Pro), 3.98 (br, $30 \mathrm{H} \alpha \mathrm{CH} \mathrm{Val}_{\mathrm{xaa}}$ ), 3.79 (br, $200 \mathrm{H} \alpha \mathrm{CH}_{2}$ Gly, $\delta \mathrm{CH} H_{2}$ Pro), 3.54 (br, $40 \mathrm{H} \delta \mathrm{CH}_{2}$ Pro), 2.80 (br , 22H $\gamma \mathrm{CH}_{2} \mathrm{Met}$ ), 2.56 (s,33H $\varepsilon \mathrm{CH}_{3}$ Met) 2.15 (br, $40 \mathrm{H} \beta \mathrm{CH}_{2} \mathrm{Pro}$ ), 1.92-1.70 (br m, 207H $\beta \mathrm{CH}_{2}$ Met, $\beta \mathrm{C} \mathrm{H}_{2}$ Pro, $\gamma \mathrm{CH}_{2}$ Pro, $\beta \mathrm{C} \mathrm{H}_{2}$ Val), 0.77 (br, $420 \mathrm{H}, \gamma \mathrm{CH}_{3}$ Val)

SEC (DMSO, LiBr 1g L-1, standard: Dextran) Mn = $20710 \mathrm{Da}, \mathrm{Mw} / \mathrm{Mn}=1.239$.

MALDI MS: theoretical MW $=18212.766 \mathrm{Da}$, experimental $[\mathrm{M}+\mathrm{H}]^{+}=18213.795 \mathrm{Da}$

UV absorption in water $\lambda_{\max }=337,633 \mathrm{~nm}$, no fluorescence.

Nuclear Magnetic Resonance (NMR): ${ }^{1} \mathrm{H}$ NMR spectra were recorded with a Bruker AVANCE III HD (Liquid-state $400 \mathrm{MHz}$ NMR spectrometer with $5 \mathrm{~mm}$ BBFO probe). Deuterated chloroform $\left(\mathrm{CDCl}_{3}\right.$, Euriso-top, $\left.99.8 \%\right)$, and deuterated water $\left(\mathrm{D}_{2} \mathrm{O}\right.$, Euri-so-top, 
99.8\%) were used as solvents and references for the lock. Bruker Topspin Software was used for data treatment.

Size Exclusion Chromatography (SEC): Measurements in DMSO were performed on an Ultimate 3000 system from Thermoscientific equipped with a diode array detector (DAD). The system also include a multi-angles light scattering detector (MALS) and differential refractive index detector (dRI) from Wyatt technology. Polymers were separated on Tosoh TSK G3000HHR and G2000HHR (7.8*300) columns (exclusion limits from $200 \mathrm{Da}$ to $60000 \mathrm{Da}$ ) at a flowrate of $0.5 \mathrm{~mL} \mathrm{~min}^{-1}$. Columns temperatures were maintained at $80{ }^{\circ} \mathrm{C}$. Dextran from PSS was used as the standard. Dimethysulfoxide (DMSO + lithium bromide LiBr $1 \mathrm{~g} \mathrm{~L}^{-1}$ ) was used as the eluent.

Sodium dodecyl sulfate - polyacrylamide gel electrophoresis (SDS-PAGE) analysis: $10 \mu \mathrm{L}$ of Precision Plus ProteinTM Standards (BIO-RAD, un-stained) was used as size marker. $15 \mu \mathrm{L}$ of sample were loaded in gel wells (BIO-RAD, 4-20\% Mini-PROTEAN® TGX ${ }^{\mathrm{TM}}$ stain-free gel). Tris-Glycine-SDS Buffer (BIO-RAD, TGS 1x) was used as loading buffer. Laemmli Sample Buffer (BIO-RAD, 2x) was used as a running buffer.

Matrix-assisted laser desorption/ionization mass spectrometry (MALDI MS): MALDI-MS spectra were performed by the CESAMO (Bordeaux, France) on an Autoflex maX TOF mass spectrometer (Bruker Daltonics, Bremen, Germany) equipped with a frequency tripled Nd:YAG laser emitting at $355 \mathrm{~nm}$. Spectra were recorded in the linear positive-ion mode with an accelerating voltage of $19 \mathrm{kV}$. Samples were dissolved in water at $4 \mathrm{mg} \mathrm{mL}^{-1}$. The SA matrix (sinapinic acid) solution was prepared by dissolving $10 \mathrm{mg}$ in $1 \mathrm{~mL}$ of acetonitrile/0.1\% aqueous TFA 50/50. The solutions were combined in a 10:10 volume ratio of matrix to sample. 
One to two microliters of the obtained solution was deposited onto the sample target and vacuum-dried.

\section{Matrix-assisted laser desorption/ionization time of flight (MALDI-TOF): MALDI-TOF} spectra were recorded using an AXIMA Confidence Shimadzu spectrometer, using trans-2-[3(4-tert-Butylphenyl)-2-methyl-2-propenylidene]malononitrile (DCTB) as a matrix.

UV-Vis spectroscopy: The transition temperatures $\left(T_{\mathrm{CP}}\right.$, cloud point) were determined by following the turbidity at 600 and $500 \mathrm{~nm}$ absorption versus temperature on Agilent Cary 100 UV-Vis spectrophotometer equipped with a multicell thermo-electric temperature controller. Turbidity has been measured over a temperature range from 10 to $65{ }^{\circ} \mathrm{C}$ at $1{ }^{\circ} \mathrm{C} \mathrm{min}{ }^{-1}$ of a scan rate before and after the TT1 conjugation at three concentrations $(10,20$ and $30 \mu \mathrm{M})$ in phosphate buffer (PBS, $\mathrm{pH}$ 7.4). The $T_{\mathrm{CP}}$ corresponds to the onset temperature where the absorbance starts increasing.

Dynamic light scattering: The DLS measurements of TT1-ELP $\left[\mathrm{M}_{1} \mathrm{~V}_{3}-40\right]$ and TT1$\operatorname{ELP}\left[\mathrm{M}(O)_{1} \mathrm{~V}_{3}-40\right]$ were performed on NanoZS 90 instrument (HeNe laser $632.8 \mathrm{~nm}$, Malvern, U.K.) at a $90^{\circ}$ angle at a constant position in the cuvette (constant scattering volume at $30 \mu \mathrm{M}$ concentration in 1x PBS, $\mathrm{pH} 7.4)$. The values of Z-average hydrodynamic diameter $\left(D_{H}\right)$ obtained from the 2 nd order cumulant fit using a CONTIN-like algorithm. The $T_{\mathrm{CP}}$ measured by DLS temperature ramp $\left(10-55^{\circ} \mathrm{C}\right)$ correspond to the onset temperature where the size and DCR starts increasing.

Atomic Force Microscopy (AFM): Temperature-controlled liquid atomic force microscopy measurements were performed using a Dimension Fast Scan Bruker AFM system. The topography images of the bioconjugates were obtained in Peak Force tapping mode, using a 
Silicon cantilever (ScanAsyst-Fluid+, Bruker) with a typical tip radius of $5 \mathrm{~nm}$. The cantilever resonance was $150 \mathrm{kHz}$ and the spring constant was $0.7 \mathrm{~N} \mathrm{~m}^{-1}$. Samples were prepared by dropcasting a bioconjugates solution of $50 \mu \mathrm{M}$ onto a freshly cleaved mica or HOPG surface purchased from Agar Scientific, which was directly applied for imaging. AFM imaging process was achieved in the liquid environment at specific temperature. An external heating stage (Bruker) was used to achieve the target temperature at the substrate surface.

Photo-irradiation experiment: $3 \mathrm{mg}$ of TT1-ELP $\left[\mathrm{M}_{1} \mathrm{~V}_{3}-40\right]$ was dissolved in $0.5 \mathrm{~mL}$ of $\mathrm{D}_{2} \mathrm{O}$ and transferred to the NMR tube. ${ }^{1} \mathrm{H}$ NMR spectra has been taken before and after every 5 min during $30 \mathrm{~min}$ of the LED (Luzchem LEDi, red region 630-640 nm, irradiance $>2100 \mathrm{~W} / \mathrm{m}^{2}$ ) irradiation to monitor the photooxidation of the methionine residue at ambient temperature via $200 \mathrm{MHz}{ }^{1} \mathrm{H} \mathrm{NMR}$.

\section{Acknowledgements}

Financial support from EuroNanoMed3 (2017-191, TEMPEAT), SIRIC BRIO (INCA, COMMUCAN project), and Spanish MICINN (T.T.) (CTQ2017-85393-P and PCIN-2017042) are gratefully acknowledged. IMDEA Nanociencia acknowledges support from the “Severo Ochoa” Program for Centers of Excellence in R\&D (MINECO, Grant SEV2016-0686). We gratefully acknowledge Gilles Pecastaings, Amelie Vax and Anne-Laure Wirotius from LCPO for liquid-AFM, SEC and NMR analysis, respectively and Christelle Absalon from CESAMO for MALDI analysis. J.A.G.D. thanks the Government of Spain for a Juan de la Cierva fellowship. Arnaud Tron and Dr. Nathan D. McClenaghan from ISM, Unversity of Bordeaux are gratefully acknowledged for providing Luzchem LEDi device to evaluate the photooxidation process.

\section{Abbreviations}


PDT, photodynamic therapy; PS, photosensitizer; ELP, elastin like polypeptide; IPT, inverse phase transition; $T_{\mathrm{t}}$, transition temperature; ITC, inverse transition cycling; EPR, enhanced permeability and retention effect; TT1, Zn(II)-phthalocyanine, [9(10),16(17),23(24)-Tri-tertbutyl-2-carboxy-5,28:14,19-diimino-7,12:21,26-

dinitrilotetrabenzo[c,h,m,r][1,6,11,16]tetraazacycloeicosinato- $\left(2^{-}\right)-N^{29}, N^{30}, N^{31}, N^{32}$ zinc (II) (mixture of regioisomers)].

\section{References}

1. Allison, R. R.; Sibata C. H., Oncologic photodynamic therapy photosensitizers: A clinical review Photodiagnosis and Photodynamic Therapy 2010, 7, 61-75.

2. Hackbarth, S.; Islam, W.; Fang, J.; Šubr, V.; Röder, B.; Etrych, T.; Maeda, H., Singlet oxygen phosphorescence detection in vivo identifies PDT-induced anoxia in solid tumors. Photochemical \& Photobiological Sciences 2019, 18 (6), 1304-1314.

3. Lukyanets, E. A., Phthalocyanines as Photosensitizers in the Photodynamic Therapy of Cancer. Journal of Porphyrins and Phthalocyanines 1999, 3 (6), 424-432.

4. Brancaleon, L.; Moseley, H., Laser and Non-laser Light Sources for Photodynamic Therapy. Lasers in Medical Science 2002, 17 (3), 173-186.

5. Moor, A. C. E.; Ortel, B.; Hasan, T., Mechanisms of photodynamic therapy. In Photodynamic Therapy, Patrice, T., Ed. The Royal Society of Chemistry 2003, 2, 19-58.

6. Hsieh, Y. J.; Chien, K. Y.; Lin, S. Y.; Sabu, S.; Hsu, R. M.; Chi, L. M.; Lyu, P. C.; Yu, J. S., Photofrin binds to procaspase-3 and mediates photodynamic treatment-triggered methionine oxidation and inactivation of procaspase-3. Cell Death \&Amp; Disease 2012, $3, \mathrm{e} 347-358$

7. Gollnick, S. O.; Evans, S. S.; Baumann, H.; Owczarczak, B.; Maier, P.; Vaughan, L.; Wang, W. C.; Unger, E.; Henderson, B. W., Role of cytokines in photodynamic therapy-induced local and systemic inflammation. British Journal of Cancer 2003, 88 (11), $1772-1779$. 
8. Castano, A. P.; Mroz, P.; Hamblin, M. R., Photodynamic therapy and anti-tumour immunity. Nature Reviews Cancer 2006, 6 (7), 535-545.

9. Kamkaew, A.; Lim, S. H.; Lee, H. B.; Kiew, L. V.; Chung, L. Y.; Burgess, K., BODIPY dyes in photodynamic therapy. Chemical Society Reviews 2013, 42 (1), 77-88.

10. Li, X.; Zheng, B.-D.; Peng, X.-H.; Li, S.-Z.; Ying, J.-W.; Zhao, Y.; Huang, J.-D.; Yoon, J., Phthalocyanines as medicinal photosensitizers: Developments in the last five years. Coordination Chemistry Reviews 2019, 379, 147-160.

11. Brasseur, N., Sensitizers for PDT: phthalocyanines. In Photodynamic Therapy, Patrice, T., Ed. The Royal Society of Chemistry 2003, 2, 105-118.

12. Almeida-Marrero, V.; Van de Winckel, E.; Anaya-Plaza, E.; Torres, T.; de la Escosura, A., Porphyrinoid biohybrid materials as an emerging toolbox for biomedical light management. Chemical Society Reviews 2018, 47 (19), 7369-7400.

13. Lo, P.-C.; Rodríguez-Morgade, M. S.; Pandey, R. K.; Ng, D. K. P.; Torres, T.; Dumoulin, F., The unique features and promises of phthalocyanines as advanced photosensitisers for photodynamic therapy of cancer. Chemical Society Reviews 2020, 49 (4), 1041-1056.

14. Ferreira, J. T.; Pina, J.; Ribeiro, C. A. F.; Fernandes, R.; Tomé, J. P. C.; RodríguezMorgade, M. S.; Torres, T., Highly Efficient Singlet Oxygen Generators Based on Ruthenium Phthalocyanines: Synthesis, Characterization and in vitro Evaluation for Photodynamic Therapy. Chemistry - A European Journal 2020, 26 (8), 1789-1799.

15. (a) Ogunsipe, A.; Nyokong, T., Effects of central metal on the photophysical and photochemical properties of non-transition metal sulfophthalocyanine. Journal of Porphyrins and Phthalocyanines 2005, 09 (02), 121-129; (b) Mwanza, D.; Louzada, M.; Britton, J.; Sekhosana, E.; Khene, S.; Nyokong, T.; Mashazi, P., The effect of the cobalt and manganese central metal ions on the nonlinear optical properties of tetra(4propargyloxyphenoxy)phthalocyanines. New Journal of Chemistry 2018, 42 (12), $9857-$ 9864.

16. Ageitos, J. M.; Chuah, J.-A.; Numata, K., Chapter 1 Design Considerations for Properties of Nanocarriers on Disposition and Efficiency of Drug and Gene Delivery. In 
Nanomedicines: Design, Delivery and Detection, The Royal Society of Chemistry 2016, $1-22$.

17. Van der Meel, R.; Sulheim, E.; Shi, Y.; Kiessling, F.; Mulder, W. J. M.; Lammers, T., Smart cancer nanomedicine. Nature Nanotechnology 2019, 14 (11), 1007-1017.

18. Ibrahimova, V.; Denisov, S. A.; Vanvarenberg, K.; Verwilst, P.; Préat, V.; Guigner, J.-M.; McClenaghan, N. D.; Lecommandoux, S.; Fustin, C.-A., Photosensitizer localization in amphiphilic block copolymers controls photodynamic therapy efficacy. Nanoscale 2017, 9 (31), 11180-11186.

19. MacEwan, S. R.; Chilkoti, A., Elastin-like polypeptides: Biomedical applications of tunable biopolymers. Peptide Science 2010, 94 (1), 60-77.

20. Rodríguez-Cabello, J. C.; Arias, F. J.; Rodrigo, M. A.; Girotti, A., Elastin-like polypeptides in drug delivery. Advanced Drug Delivery Reviews 2016, 97, 85-100.

21. Urry, D. W.; Physical Chemistry of Biological Free Energy Transduction As Demonstrated by Elastic Protein-Based Polymers. J. Phys. Chem. B 1997, 101 (51), $11007-11028$.

22. Petitdemange, R.; Garanger, E.; Bataille, L.; Dieryck, W.; Bathany, K.; Garbay, B.; Deming, T. J.; Lecommandoux, S., Selective Tuning of Elastin-like Polypeptide Properties via Methionine Oxidation. Biomacromolecules 2017, 18 (2), 544-550.

23. Aluri, S.; Pastuszka, M. K.; Moses, A. S.; MacKay, J. A., Elastin-Like Peptide Amphiphiles Form Nanofibers with Tunable Length. Biomacromolecules 2012, 13 (9), $2645-2654$.

24. Mozhdehi, D.; Luginbuhl, K. M.; Simon, J. R.; Dzuricky, M.; Berger, R.; Varol, H. S.; Huang, F. C.; Buehne, K. L.; Mayne, N. R.; Weitzhandler, I. et al., Genetically encoded lipid-polypeptide hybrid biomaterials that exhibit temperature-triggered hierarchical selfassembly. Nature Chemistry 2018, 10 (5), 496-505.

25. Petitdemange, R.; Garanger, E.; Bataille, L.; Bathany, K.; Garbay, B.; Deming, T. J.; Lecommandoux, S., Tuning Thermoresponsive Properties of Cationic Elastin-like Polypeptides by Varying Counterions and Side-Chains. Bioconjugate Chemistry 2017, 28 (5), 1403-1412. 
26. Kramer, J. R.; Petitdemange, R.; Bataille, L.; Bathany, K.; Wirotius, A.-L.; Garbay,

B.; Deming, T. J.; Garanger, E.; Lecommandoux, S., Quantitative Side-Chain Modifications of Methionine-Containing Elastin-Like Polypeptides as a Versatile Tool to Tune Their Properties. ACS Macro Lett. 2015, 4, 1283-1286

27. Xiao, Y.; Chinoy, Z. S.; Pecastaings, G.; Bathany, K.; Garanger, E.; Lecommandoux, S., Design of Polysaccharide-b-Elastin-Like Polypeptide Bioconjugates and Their Thermoresponsive Self-Assembly. Biomacromolecules 2020, 21, 114-125.

28. Rosselin, M.; Xiao, Y.; Belhomme, L.; Lecommandoux, S.; Garanger, E., Expanding the Toolbox of Chemoselective Modifications of Protein-Like Polymers at Methionine Residues. ACS Macro Letters 2019, 1648-1653.

29. Bravo-Anaya, L. M.; Garbay, B.; Nando-Rodríguez, J. L. E.; Carvajal Ramos, F.; Ibarboure, E.; Bathany, K.; Xia, Y.; Rosselgong, J.; Joucla, G.; Garanger, E. et al., Nucleic acids complexation with cationic elastin-like polypeptides: Stoichiometry and stability of nano-assemblies. Journal of Colloid and Interface Science 2019, 557, 777-792.

30. Anaya, L. M. B.; Petitdemange, R.; Rosselin, M.; Ibarboure, E.; Garbay, B.; Garanger, E.; Deming, T. J.; Lecommandoux, S., Design of Thermoresponsive ElastinLike Glycopolypeptides for Selective Lectin Binding and Sorting. Biomacromolecules 2020, 22 (1), 76-85.

31. Cid, J.-J.; Yum, J.-H.; Jang, S.-R.; Nazeeruddin, M. K.; Martínez-Ferrero, E.; Palomares, E.; Ko, J.; Grätzel, M.; Torres, T., Molecular Cosensitization for Efficient Panchromatic Dye-Sensitized Solar Cells. Angewandte Chemie International Edition 2007, $46(44), 8358-8362$.

32. Ylä-Herttuala, S.; Christensen, J. B.; Moghimi, S.M.; Torres Cebada, T.; Trohopoulos, P. N.; Makinen, P.; Ficker, M.; Wu, L.; Medel Gonzalez, M., Nano-systems for therapy and/or diagnosis and/or therapy Monitoring and/or theranostics of disease, PCT/EP 16168476.6., 05/05/2016.

33. Aktas, E.; Jiménez-López, J.; Azizi, K.; Torres, T.; Palomares, E., Self-assembled Zn phthalocyanine as a robust p-type selective contact in perovskite solar cells. Nanoscale Horizons 2020, 5, 1415-1419 
34. Meyer, D. E.; Chilkoti, A., Purification of recombinant proteins by fusion with thermally-responsive polypeptides. Nature Biotechnology 1999, 17 (11), 1112-1115.

35. Ye, C.; Zhang, Y.; Ding, A.; Hu, Y.; Guo, H., Visible light sensitizer-catalyzed highly selective photo oxidation from thioethers into sulfoxides under aerobic condition. Scientific Reports 2018, 8 (1), 2205-2211.

36. Kim, H.-Y.; Gladyshev, Vadim N., Methionine sulfoxide reductases: selenoprotein forms and roles in antioxidant protein repair in mammals. Biochemical Journal 2007, 407 (3), 321-329.

37. Meyer, D. E.; Chilkoti, A., Genetically Encoded Synthesis of Protein-Based Polymers with Precisely Specified Molecular Weight and Sequence by Recursive Directional Ligation: Examples from the Elastin-like Polypeptide System. Biomacromolecules 2002, 3 (2), 357-367.

38. Le, D. H. T.; Sugawara-Narutaki, A., Elastin-like polypeptides as building motifs toward designing functional nanobiomaterials. Molecular Systems Design \& Engineering 2019, 4 (3), 545-565.

39. Schüder, G.; Pistorius, G.; Fehringer, M.; Feifel, G.; Menger, M. D.; Vollmar, B., Complete shutdown of microvascular perfusion upon hepatic cryothermia is critically dependent on local tissue temperature. British Journal of Cancer 2000, 82 (4), 794-799.

40. Ibáñez-Fonseca, A.; Santiago Maniega, S.; Gorbenko del Blanco, D.; Catalán Bernardos, B.; Vega Castrillo, A.; Álvarez Barcia, Á. J.; Alonso, M.; Aguado, H. J.; Rodríguez-Cabello, J. C., Elastin-Like Recombinamer Hydrogels for Improved Skeletal Muscle Healing Through Modulation of Macrophage Polarization. Frontiers in Bioengineering and Biotechnology 2020, 8, 413-424.

41. McDaniel, J. R.; Callahan, D. J.; Chilkoti, A., Drug delivery to solid tumors by elastin-like polypeptides. Adv. Drug Deliv. Rev. 2010, 62 (15), 1456-1467.

42. Manzari, M. T.; Anderson, G. R.; Lin, K. H.; Soderquist, R. S.; Çakir, M.; Zhang, M.; Moore, C. E.; Skelton, R. N.; Fèvre, M., Li, X. et al., Genomically informed smallmolecule drugs overcome resistance to a sustained-release formulation of an engineered 
Author manuscript of article published in Bioconjugate Chemistry (2021) https://doi.org/10.1021/acs.bioconjchem.1c00251

death receptor agonist in patient-derived tumor models. Sci. Adv. 2019, 5 (9), eaaw91629176. 


\section{Photooxidation Responsive Elastin-Like Polypeptide}

\section{Conjugates for Photodynamic Therapy Application}

Vusala Ibrahimova, ${ }^{\dagger}$ José A. González-Delgado, ${ }^{\ddagger}$ Manon Levêque, ${ }^{\dagger}$ Tomas Torres, *\$, ॥, § Elisabeth Garanger, ${ }^{* \dagger}$ and Sébastien Lecommandoux*†

$\dagger$ Univ. Bordeaux, CNRS, Bordeaux INP, LCPO, UMR 5629, F-33600, Pessac, France

* Departamento de Química Orgánica, Universidad Autónoma de Madrid, 28049 Madrid, Spain

" IMDEA-Nanociencia, Campus de Cantoblanco, 28049 Madrid, Spain

$\S$ Institute for Advanced Research in Chemical Sciences (IAdChem), Universidad Autónoma de Madrid, 28049 Madrid, Spain

Corresponding authors: $\quad$ lecommandoux@enscbp.fr; $\quad$ garanger@enscbp.fr; tomas.torres@uam.es

TT1-amide-C3-azide (1)

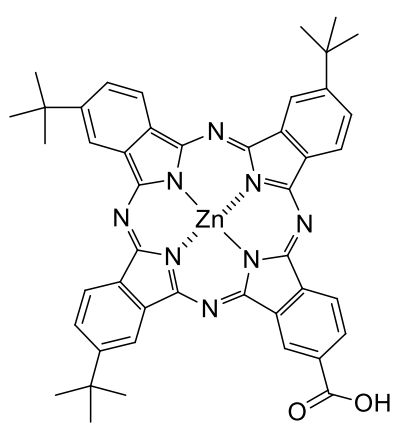

TT1

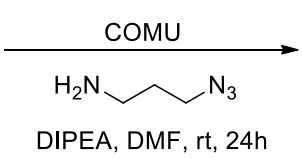

DIPEA, DMF, rt, 24h

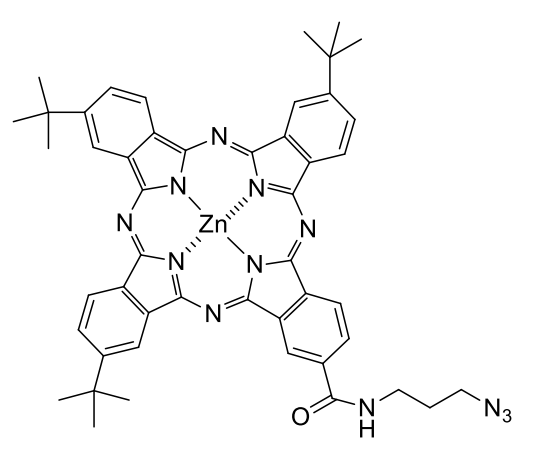

1

Scheme S1. Synthesis of TT1-amide-C3-azide (1).

Reagents: 9(10),16(17),23(24)-Tri-tert-butyl-2-carboxy-5,28:14,19-diimino-7,12:21,26dinitrilo-tetrabenzo[c, h, m,r] $[1,6,11,16]$ tetraazacycloeicosinato- $\left(2^{-}\right)-N^{29}, N^{30}, N^{31}, N^{32}$ zinc (II) 
(mixture of regioisomers) (TT1), 3-azidopropylamine $\left(\mathrm{C}_{3} \mathrm{H}_{8} \mathrm{~N}_{4}\right.$, TCI Europe, $>95.0 \%$ ), $\mathrm{COMU} \otimes\left(\mathrm{C}_{12} \mathrm{H}_{19} \mathrm{~F}_{6} \mathrm{~N}_{4} \mathrm{O}_{4} \mathrm{P}\right.$, Sigma-Aldrich, 97\%)

Solvents: 1,4-dioxane (HPLC - Stabilized with BHT, Carlo Erba), n-hexane (99\% for analysis, Carlo Erba)

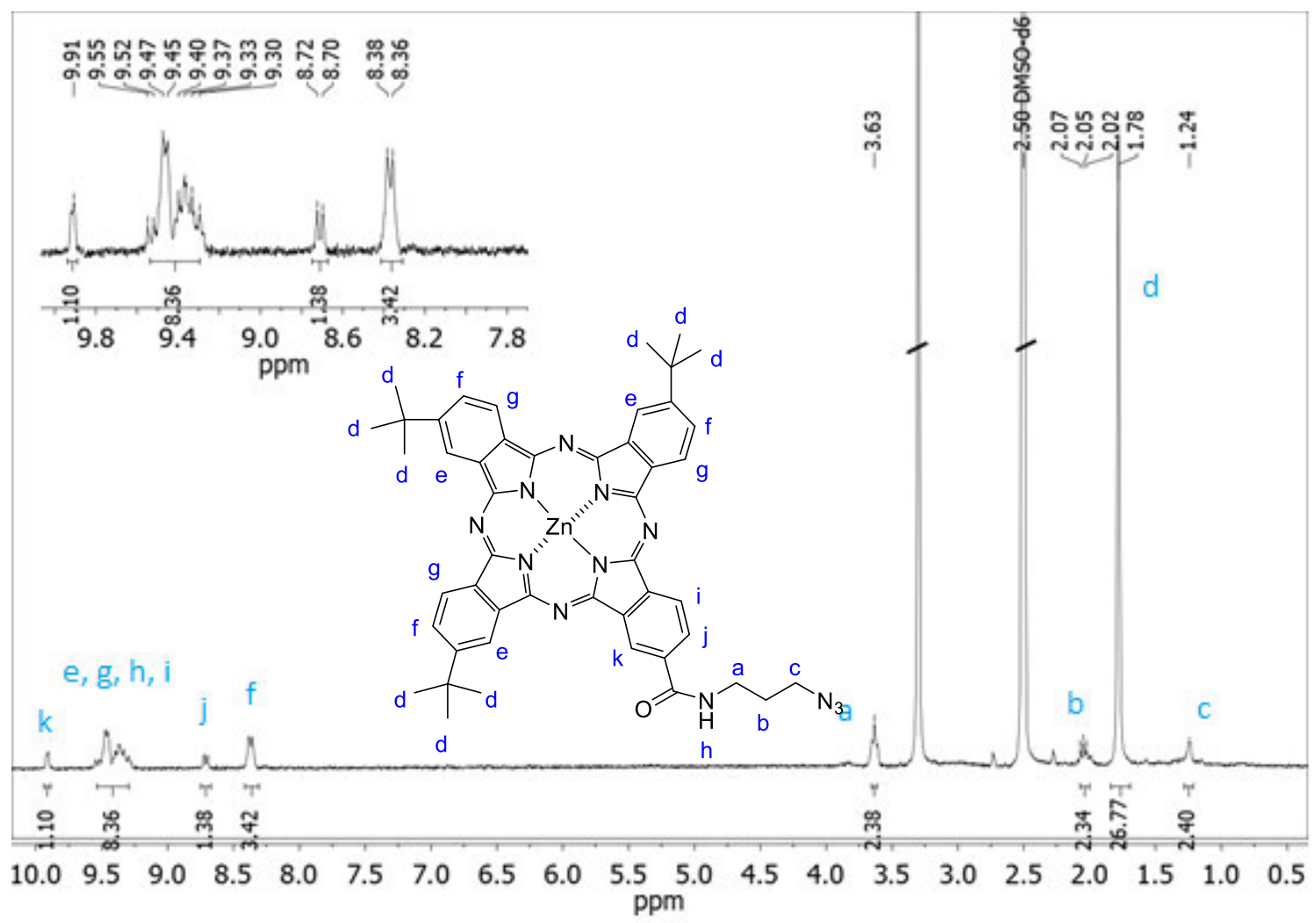

Figure S1. ${ }^{1} \mathrm{H}$ NMR spectrum of TT1-amide-C3-azide (1) (DMSO-d $\left.{ }_{6}\right)$. 


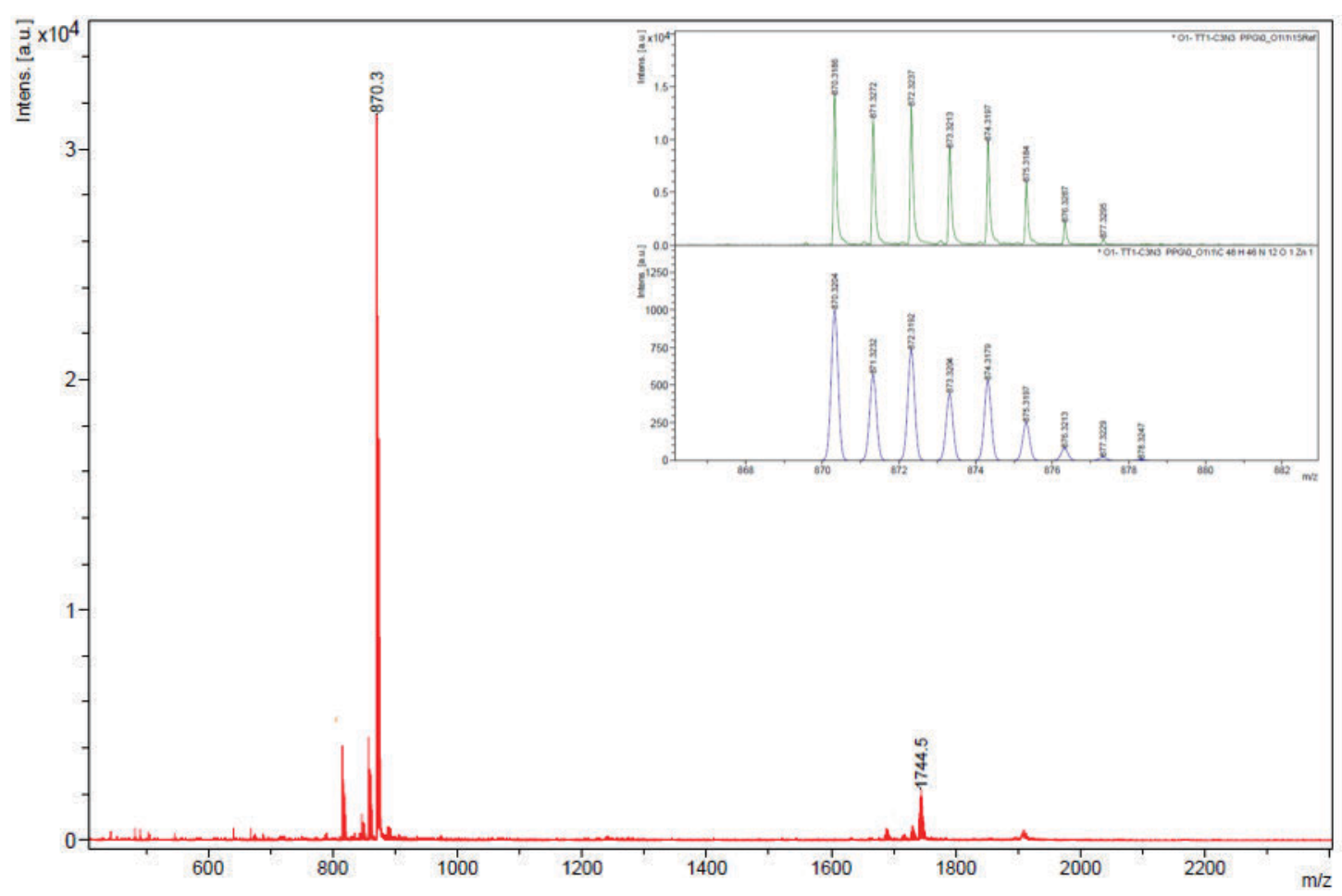

Figure S2. MS and HRMS (MALDI-TOF, DCTB) of TT1-amide-C3-azide (1)

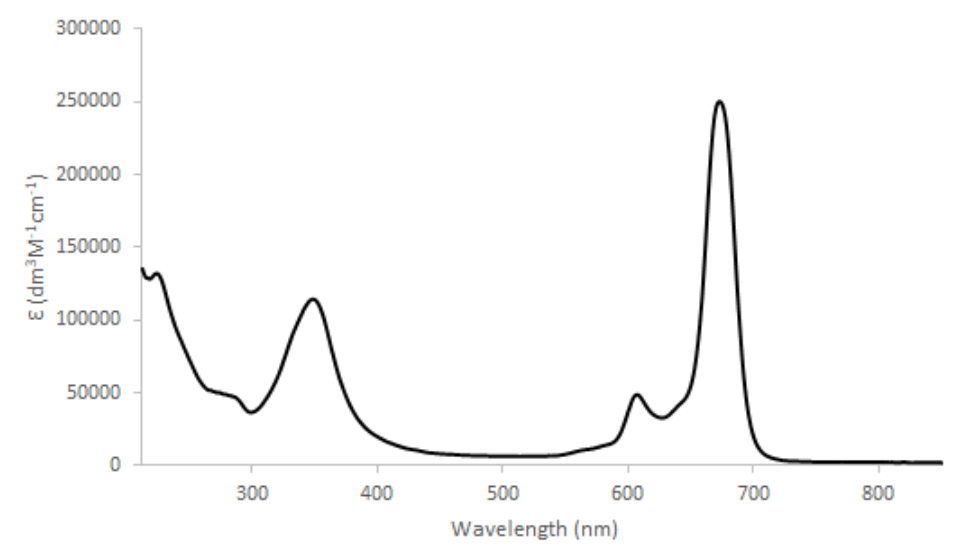

Figure S3. UV-Vis spectrum of TT1-amide-C3-azide (1) in THF (Concentration $2,14 \cdot 10^{-6} \mathrm{M}$ ). 

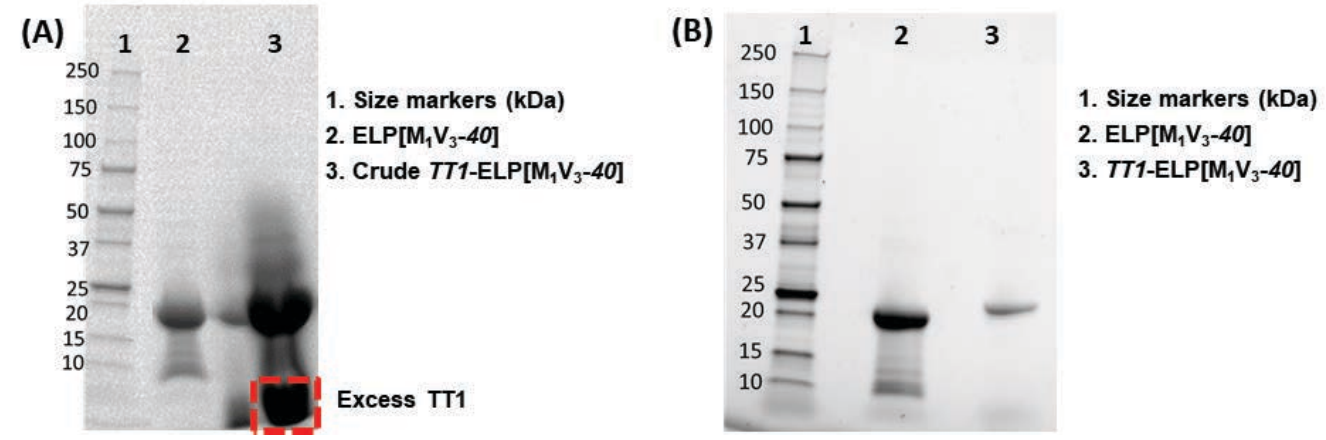

Figure S4. SDS-PAGE analysis of TT1-ELP $\left[\mathrm{M}_{1} \mathrm{~V}_{3}-40\right]$ (A) before and (B) after purification.

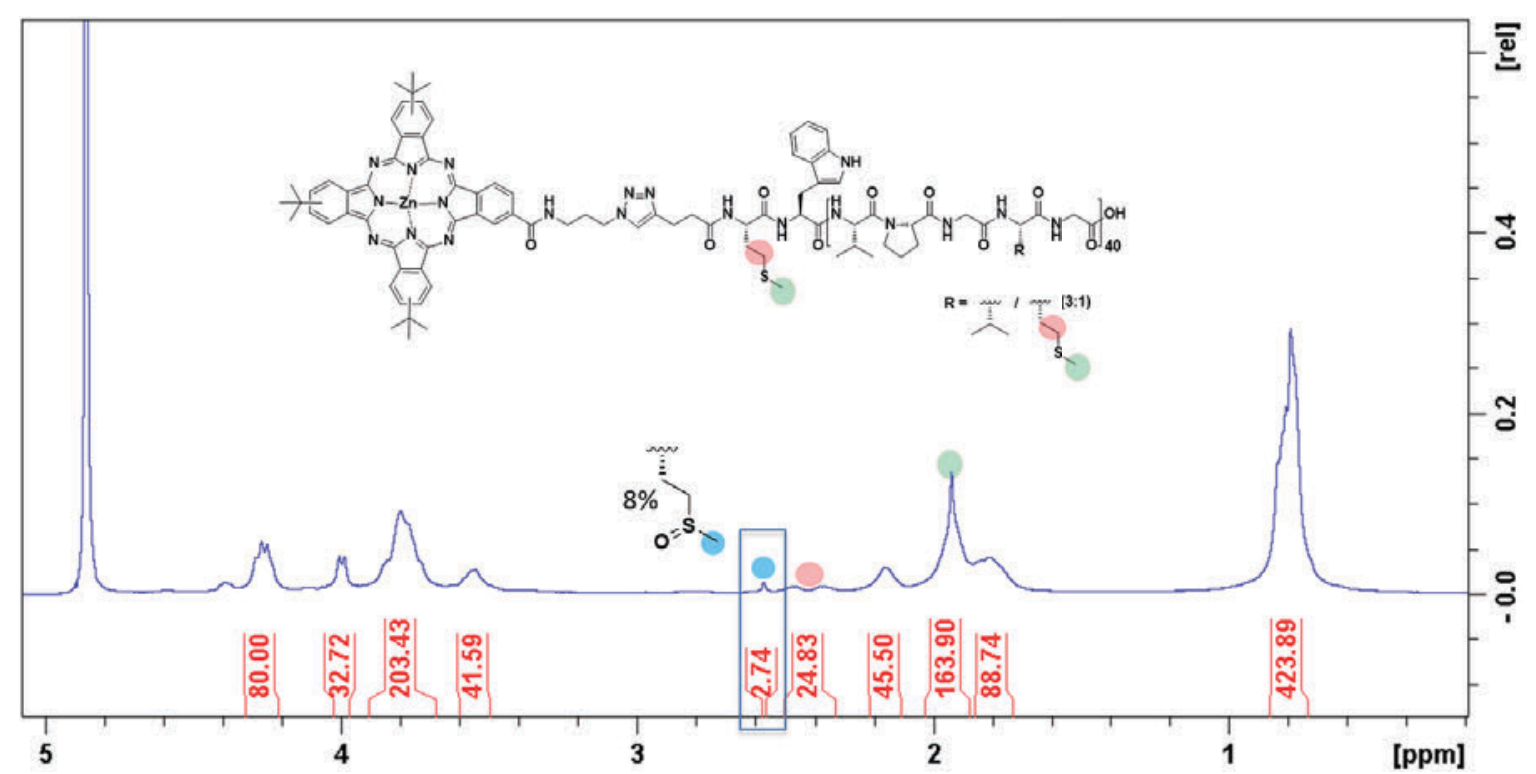

Figure S5. ${ }^{1} \mathrm{H}$ NMR spectrum of $T T 1-\mathrm{ELP}\left[\mathrm{M}_{1} \mathrm{~V}_{3}-40\right]$ in $\mathrm{D}_{2} \mathrm{O}$ at $5{ }^{\circ} \mathrm{C}$. 


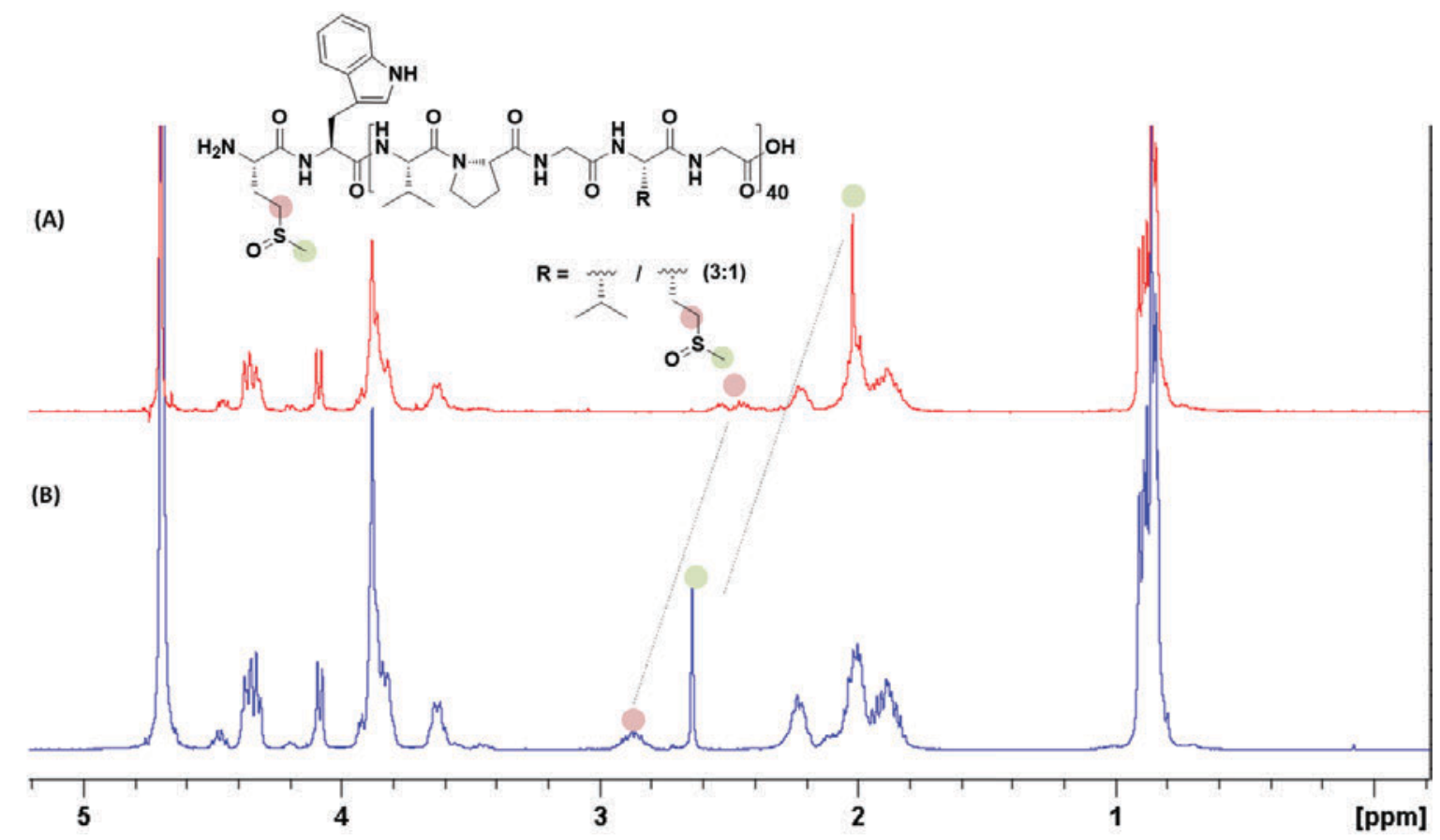

Figure S6. ${ }^{1} \mathrm{H}$ NMR spectrum of $\operatorname{ELP}\left[\mathrm{M}(O)_{1} \mathrm{~V}_{3}-40\right]$, (A) before and (B) after the chemical oxidation, in $\mathrm{D}_{2} \mathrm{O}$ at room temperature.

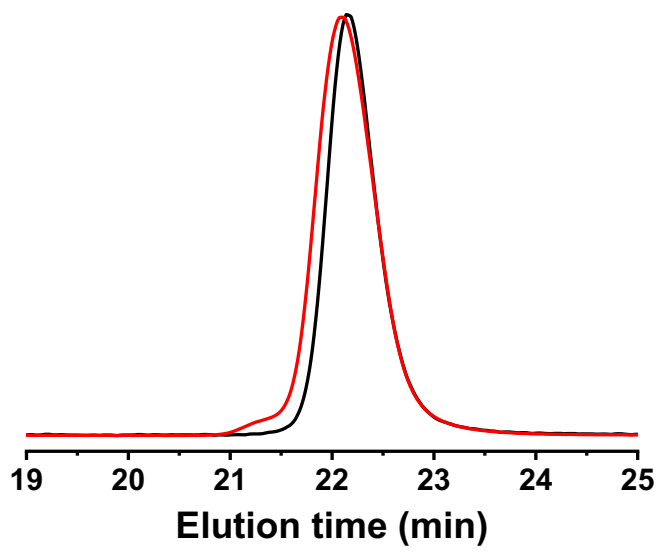

Figure S7. Size exclusion chromatograms (RI detection) in DMSO of ELP $\left[\mathrm{M}_{1} \mathrm{~V}_{3}-40\right]$ (black curve) and $\operatorname{ELP}\left[\mathrm{M}(O)_{1} \mathrm{~V}_{3}-40\right]$ (red curve). 


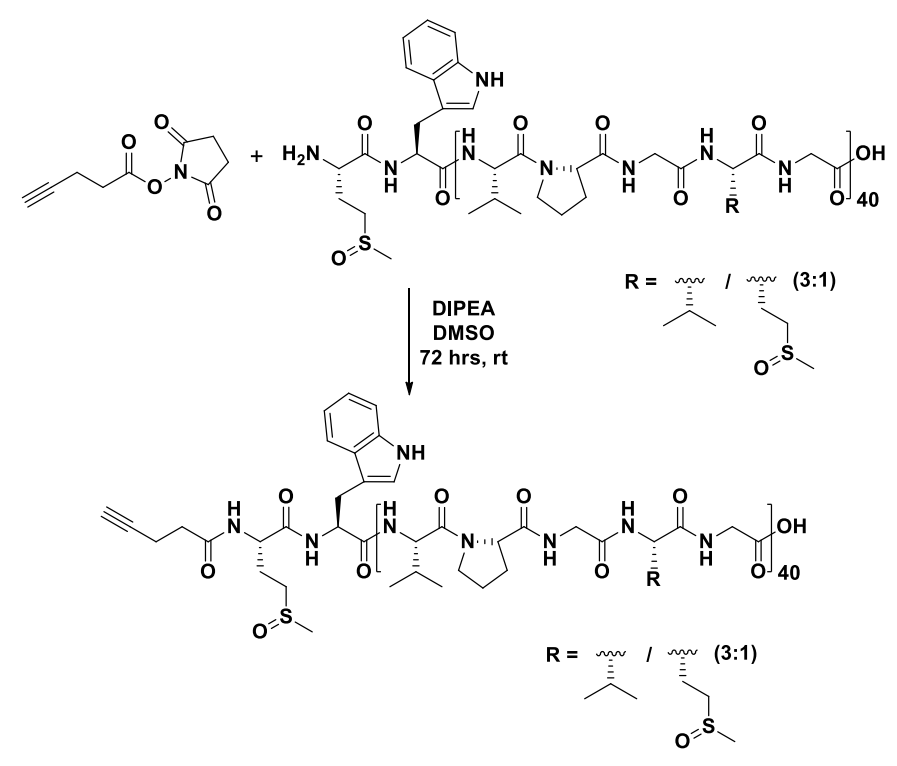

Scheme S2. Synthesis of Alkyne-ELP $\left[\mathrm{M}(O)_{1} \mathrm{~V}_{3}-40\right]$.

To a solution of ELP $\left[\mathrm{M}(O){ }_{1} \mathrm{~V}_{3}-40\right](40 \mathrm{mg}, 2.32 \mu \mathrm{mol})$ in anhydrous DMSO $(2 \mathrm{~mL}) \mathrm{N}, \mathrm{N}$ diisopropylethylamine $(0.3 \mathrm{mg}, 2.32 \mu \mathrm{mol})$ was added and followed by addition of 4-pentynoic acid succinimidyl ester $(9 \mathrm{mg}, 46.48 \mu \mathrm{mol})$. The reaction mixture was stirred for $72 \mathrm{~h}$ under Ar at room temperature. Then the solution was diluted with $15 \mathrm{~mL}$ of water and dialyzed against ultrapure water in a dialysis bag (cut-off MWCO $3.5 \mathrm{kDa}$ ) for $72 \mathrm{~h}$ by changing the water every $3 \mathrm{~h}$. The solution was lyophilized to yield Alkyne-ELP $\left[\mathrm{M}(O)_{1} \mathrm{~V}_{3}-40\right](30 \mathrm{mg}, 75 \%)$ as a white powder.

${ }^{1} \mathrm{H}$ NMR (400 MHz, $\left.\mathrm{D}_{2} \mathrm{O}, 25^{\circ} \mathrm{C}\right): \delta 4.29-4.23$ (m, $80 \mathrm{H}, \alpha \mathrm{CH}$ Val, Pro), 4.09-3.99 (d, $30 \mathrm{H}$, $\alpha \mathrm{CH}$ VPGVG), 2.85-2.73 (m, $22 \mathrm{H}, \mathrm{CH}_{2} \mathrm{~S}$ Met), 2.38-2.29 (br m, $\gamma \mathrm{CH}_{2} \mathrm{Met}, \mathrm{CH}_{2} \mathrm{CH}_{2} \mathrm{C} \equiv \mathrm{CH}$ ), 2.56 (s, $33 \mathrm{H}, \mathrm{SCH}_{3} \mathrm{Met}$ ), 0.82-0.75 (br m, $420 \mathrm{H}, \mathrm{CH}_{3} \mathrm{Val}$ ). 


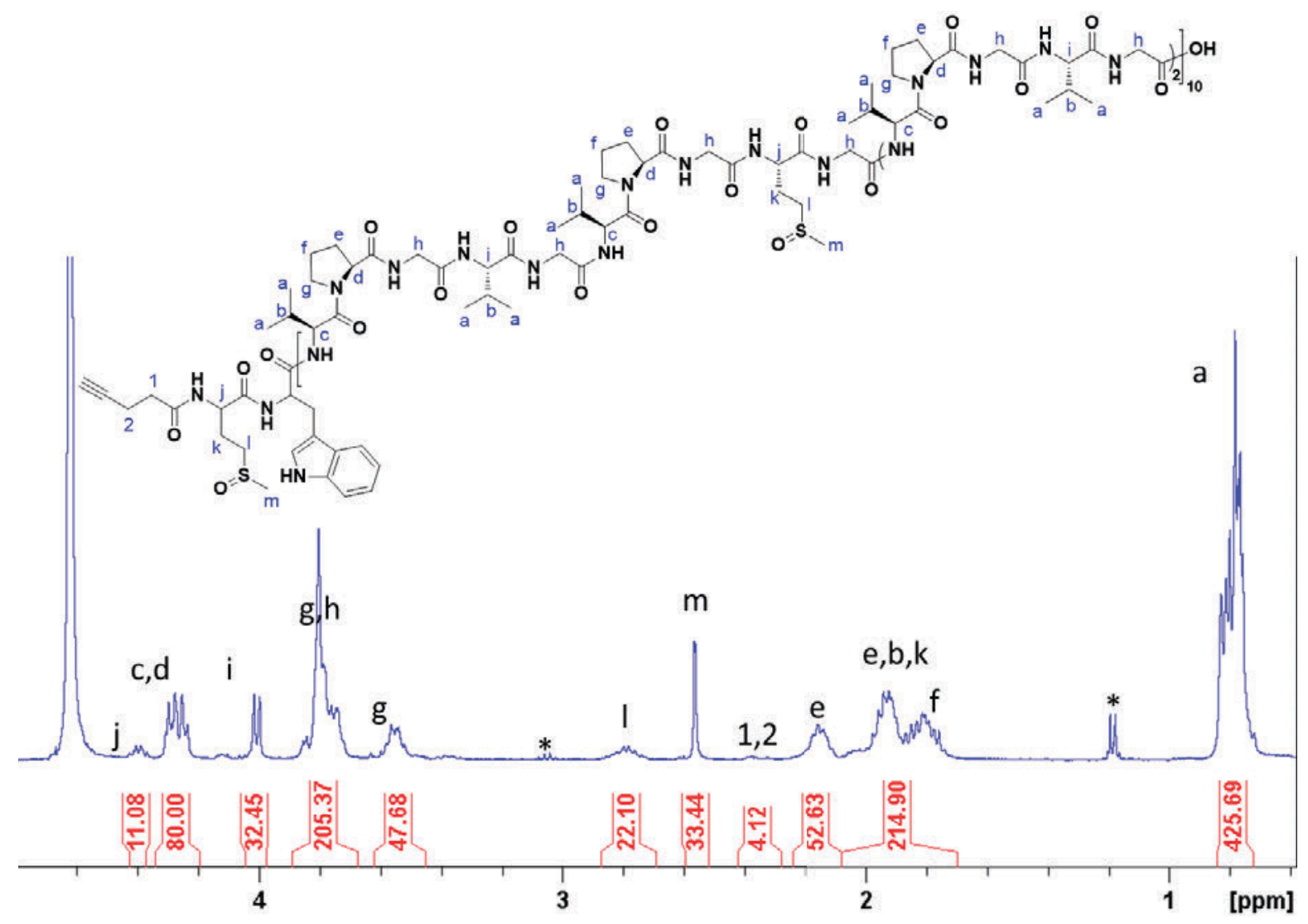

Figure S8. ${ }^{1} \mathrm{H}$ NMR spectrum of Alkyne-ELP $\left[\mathrm{M}(O)_{1} \mathrm{~V}_{3}-40\right]$ in $\mathrm{D}_{2} \mathrm{O}$ at room temperature (*EtOH).

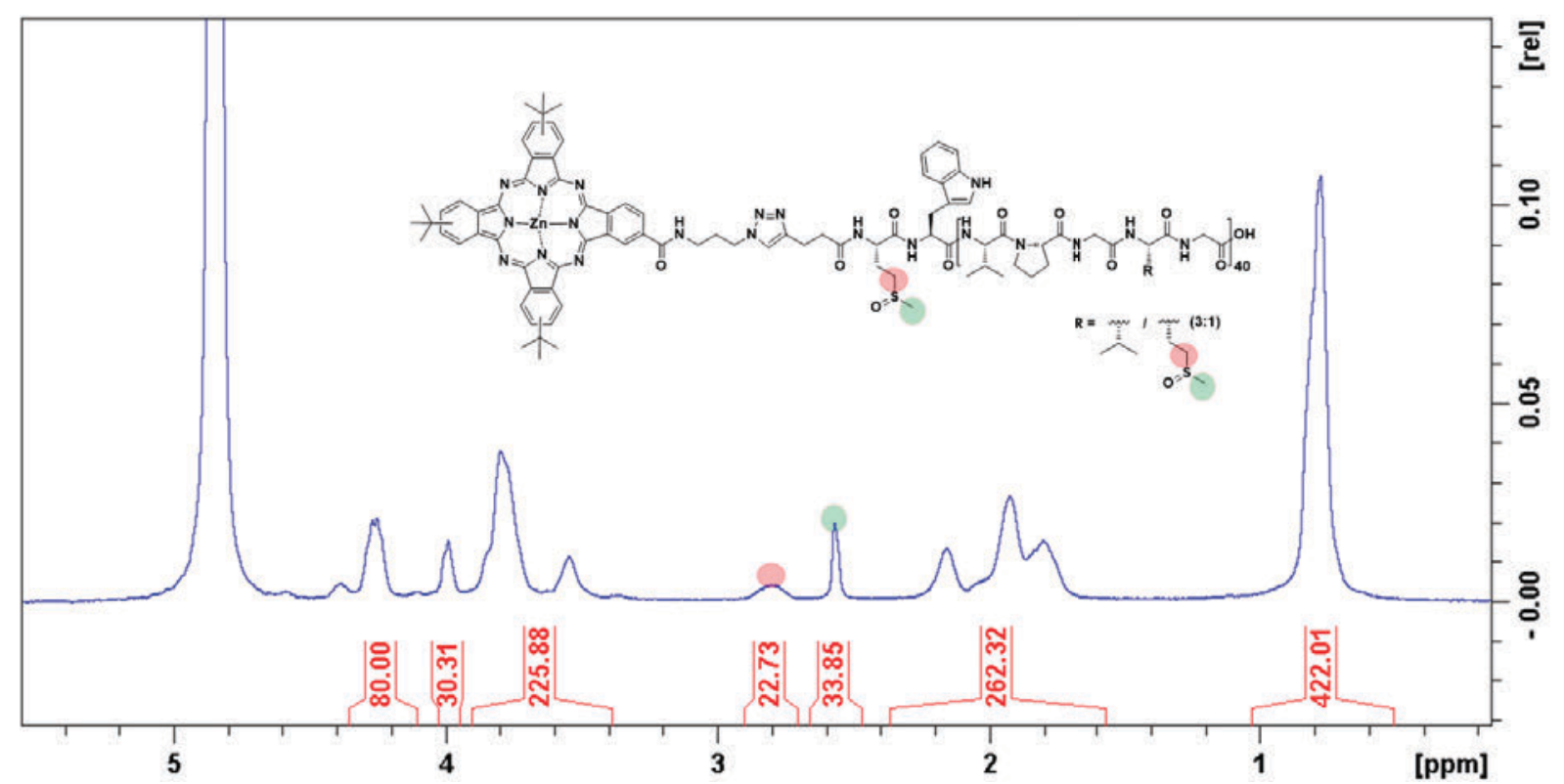

Figure S9. ${ }^{1} \mathrm{H}$ NMR spectrum of $T T 1-\operatorname{ELP}\left[\mathrm{M}(O){ }_{1} \mathrm{~V}_{3}-40\right]$ in $\mathrm{D}_{2} \mathrm{O}$ at $5{ }^{\circ} \mathrm{C}$. 


\section{$10 \mu \mathrm{M}$ solutions in PBS}

-10 to $65^{\circ} \mathrm{C}$

- 65 to $10^{\circ} \mathrm{C}$

(A)

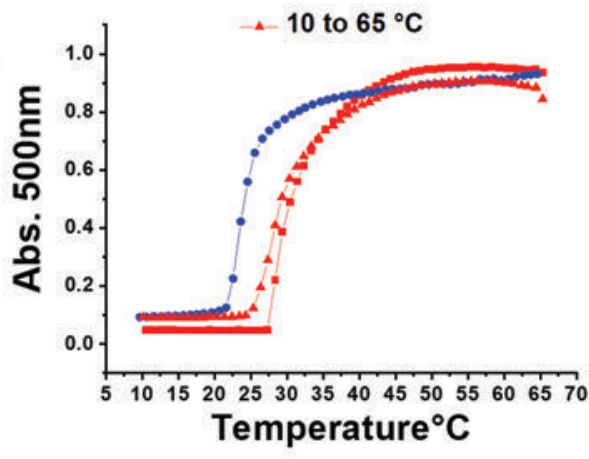

(B)

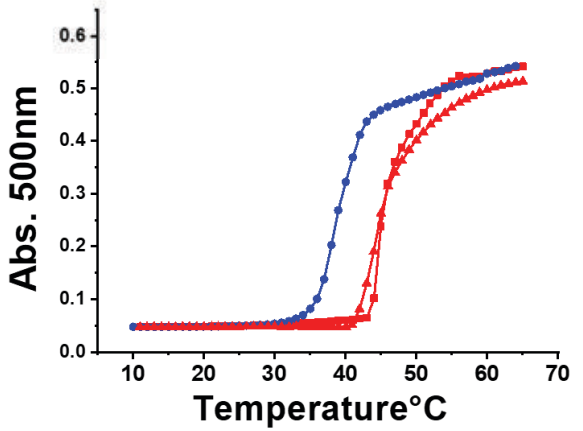

(C)

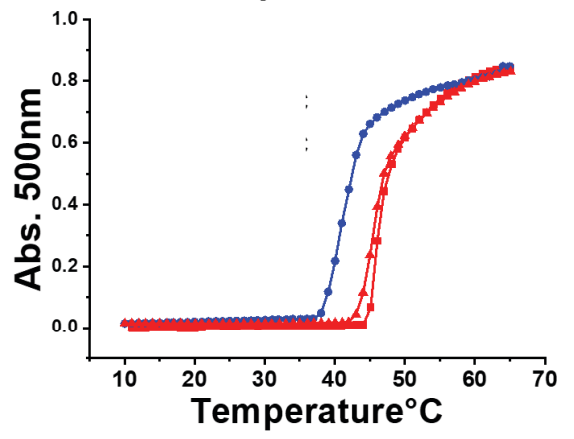

\section{Different concentration}

$-10 \mu \mathrm{M}$

$-20 \mu \mathrm{M}$

$-\mathbf{- 3 0 \mu \mathrm { M }}$

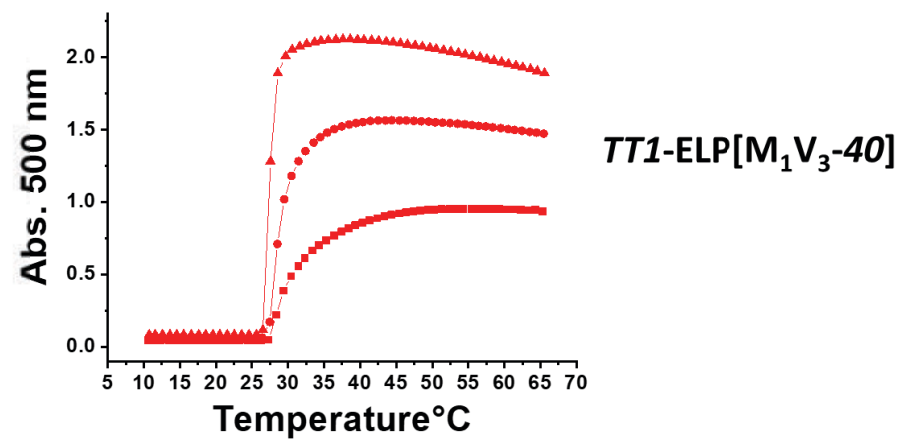

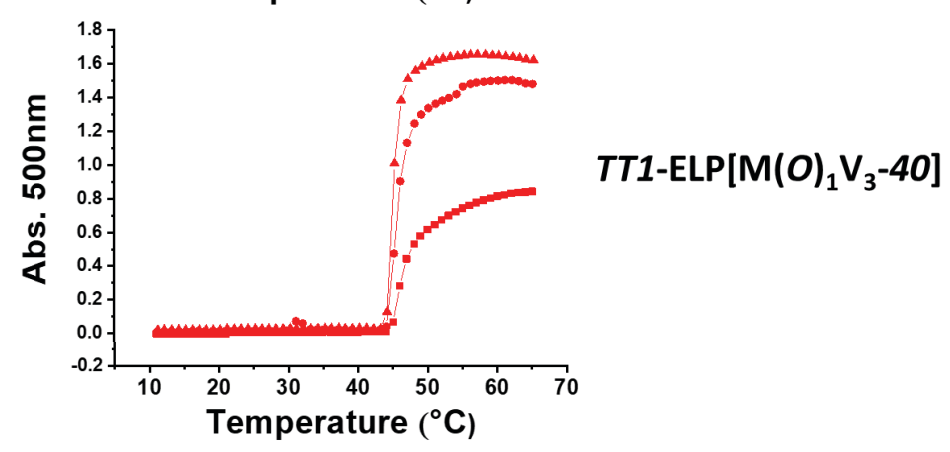

Figure S10. Absorbance (A.U.) at $500 \mathrm{~nm}$ of (A) TT1-ELP[M $\left.\mathrm{M}_{1} \mathrm{~V}_{3}-40\right]$, (B) TT1-ELP[M $\left.\mathrm{M}_{1} \mathrm{~V}_{3}-40\right]$ photooxidized, noted TT1-ELP $\left[\mathrm{M}_{1} \mathrm{~V}_{3}-40\right]^{\mathrm{PhOx}}$, and (C) TT1-ELP[M $\left.(O)_{1} \mathrm{~V}_{3}-40\right]$ solutions upon heating-cooling-heating $\left(10-65^{\circ} \mathrm{C}\right)$ cycles at $10 \mu \mathrm{M}$ (left panels) and upon heating at $10 \mu \mathrm{M}$, $20 \mu \mathrm{M}$ and $30 \mu \mathrm{M}$ concentrations (right panels) in PBS as a function of temperature.

(A)

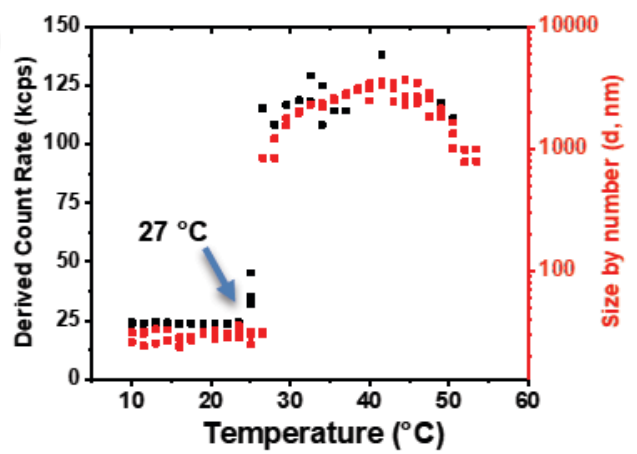

(B)

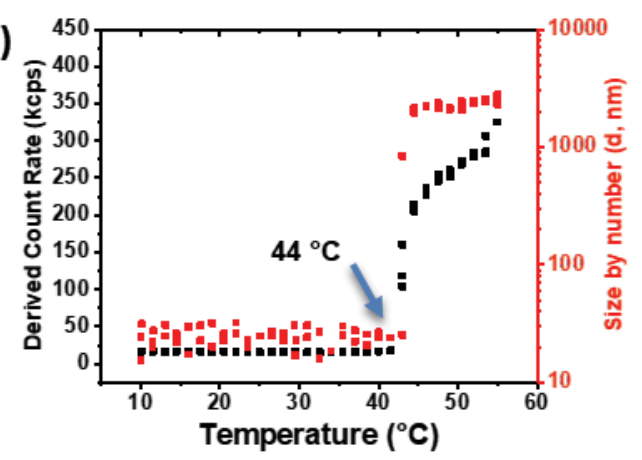


Figure S11. Temperature ramp results of (A) TT1-ELP $\left[\mathrm{M}_{1} \mathrm{~V}_{3}-40\right]$ and (B) TT1-ELP $\left[\mathrm{M}(O)_{1} \mathrm{~V}_{3}-\right.$ 40] solutions at $30 \mu \mathrm{M}$ concentration in PBS buffer upon heating at a range of $10-55^{\circ} \mathrm{C}\left(1.5^{\circ} \mathrm{C}\right.$ step, $n=3$ ) measured by DLS at $90^{\circ}$ angle.

(A)

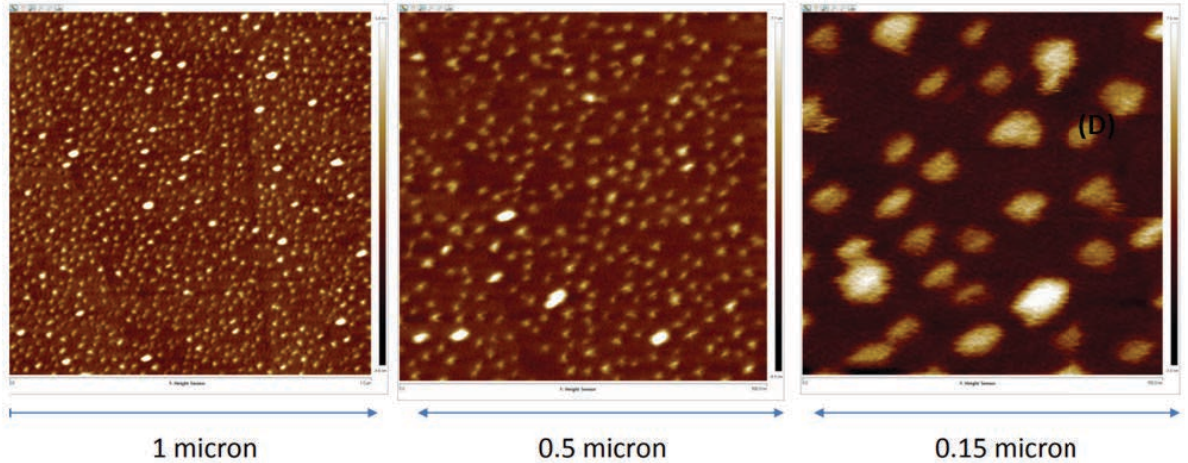

(B)

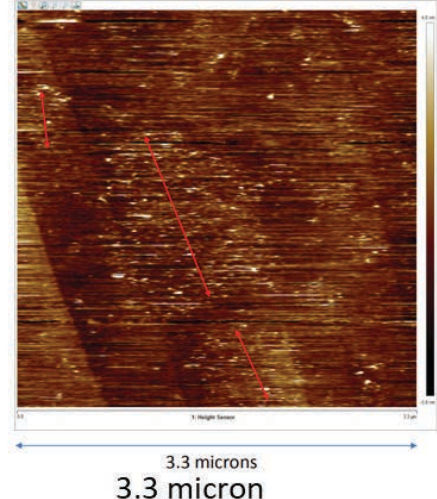

(C)

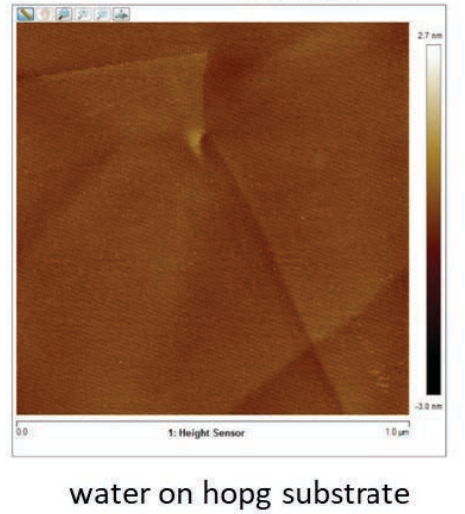

Figure S12. Temperature-Controlled High-Speed AFM (liquid) images of TT1-ELP[M $\left.\mathrm{M}_{1} \mathrm{~V}_{3}-40\right]$ on HOPG substrate (A) at $15{ }^{\circ} \mathrm{C}$, (B) at $50{ }^{\circ} \mathrm{C}$ in PBS and (C) pure water on HOPG substrate.

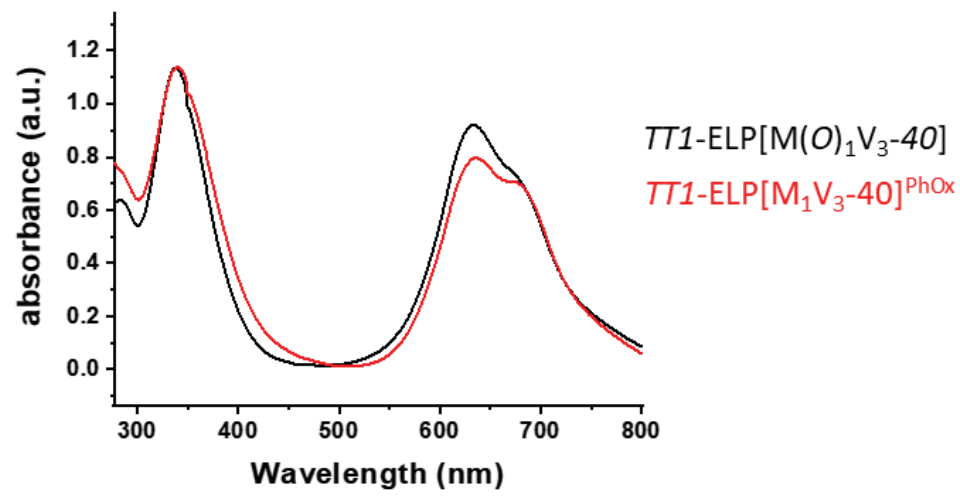

Figure S13. Overlapped absorption spectra of TT1-ELP $\left[\mathrm{M}(O)_{1} \mathrm{~V}_{3}-40\right]$ (black curve) and TT1ELP $\left[\mathrm{M}_{1} \mathrm{~V}_{3}-40\right]^{\mathrm{PhOx}}$ (red curve) in water. 


\section{Photooxidation Responsive Elastin-Like Polypeptide}

\section{Conjugates for Photodynamic Therapy Application}

Vusala Ibrahimova, ${ }^{\dagger}$ José A. González-Delgado, ${ }^{\ddagger}$ Manon Levêque, ${ }^{\dagger}$ Tomas Torres, ${ }^{*}{ }^{\ddagger}, \|$, $\S$ Elisabeth Garanger, ${ }^{* \dagger}$ and Sébastien Lecommandoux*广

$\dagger$ Univ. Bordeaux, CNRS, Bordeaux INP, LCPO, UMR 5629, F-33600, Pessac, France

\$ Departamento de Química Orgánica, Universidad Autónoma de Madrid, 28049 Madrid, Spain

"IMDEA-Nanociencia, Campus de Cantoblanco, 28049 Madrid, Spain

$\S$ Institute for Advanced Research in Chemical Sciences (IAdChem), Universidad Autónoma de Madrid, 28049 Madrid, Spain

Corresponding authors: lecommandoux@enscbp.fr; garanger@enscbp.fr; tomas.torres@uam.es

TT1-amide-C3-azide (1)
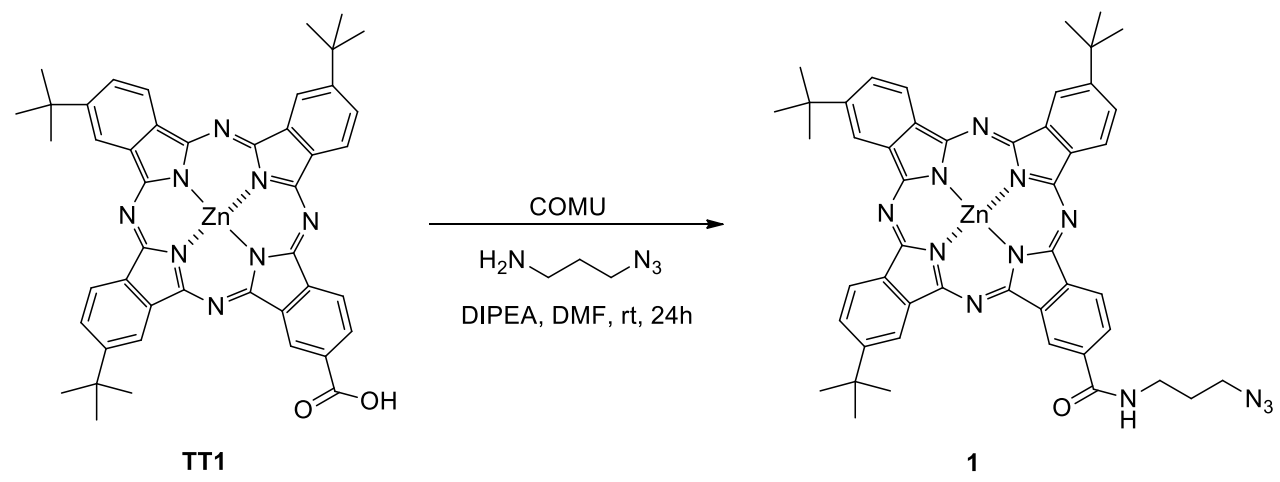

Scheme S1. Synthesis of TT1-amide-C3-azide (1). 
Reagents: 9(10),16(17),23(24)-Tri-tert-butyl-2-carboxy-5,28:14,19-diimino-7,12:21,26-dinitrilotetrabenzo[c,h,m,r][1,6,11,16]tetraazacycloeicosinato- $\left(2^{-}\right)-N^{29}, N^{30}, N^{31}, N^{32}$ zinc (II) (mixture of regioisomers) (TT1), 3-azidopropylamine $\left(\mathrm{C}_{3} \mathrm{H}_{8} \mathrm{~N}_{4}, \quad\right.$ TCI Europe, $\left.>95.0 \%\right)$, COMU® $\left(\mathrm{C}_{12} \mathrm{H}_{19} \mathrm{~F}_{6} \mathrm{~N}_{4} \mathrm{O}_{4} \mathrm{P}\right.$, Sigma-Aldrich, 97\%)

Solvents: 1,4-dioxane (HPLC - Stabilized with BHT, Carlo Erba), n-hexane (99\% for analysis, Carlo Erba)

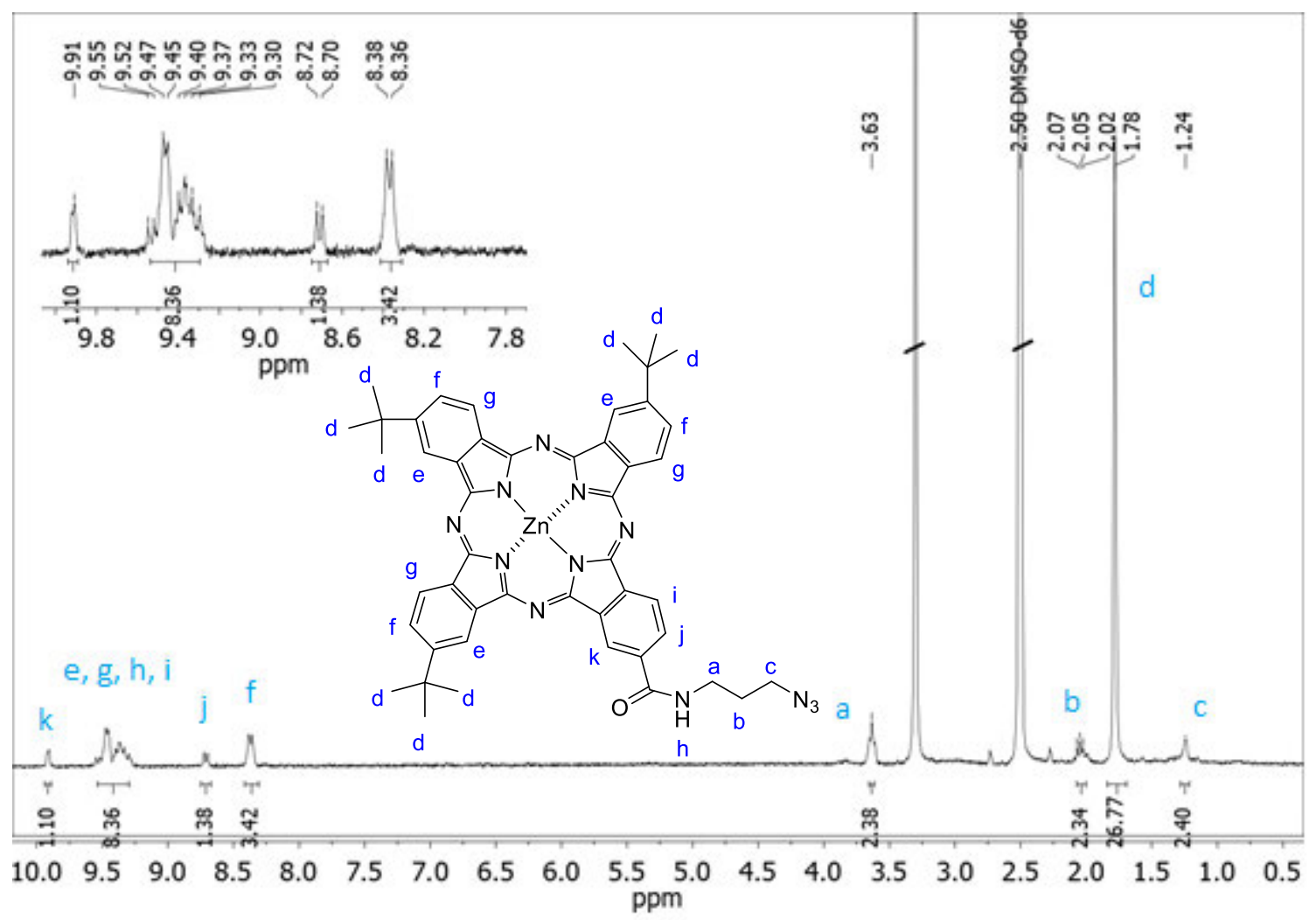

Figure S1. ${ }^{1} \mathrm{H}$ NMR spectrum of TT1-amide-C3-azide (1) (DMSO-d 6 ). 


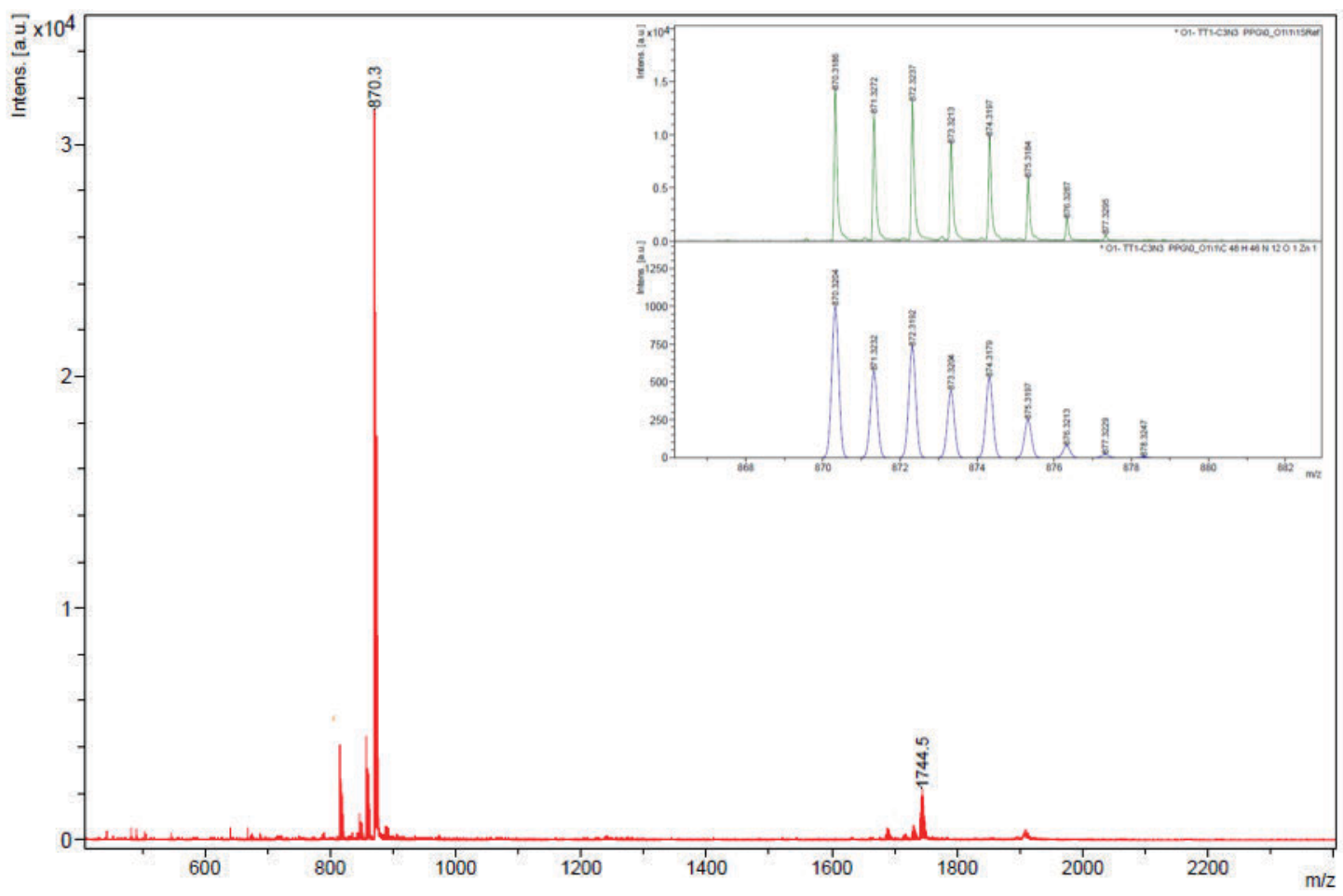

Figure S2. MS and HRMS (MALDI-TOF, DCTB) of TT1-amide-C3-azide (1)

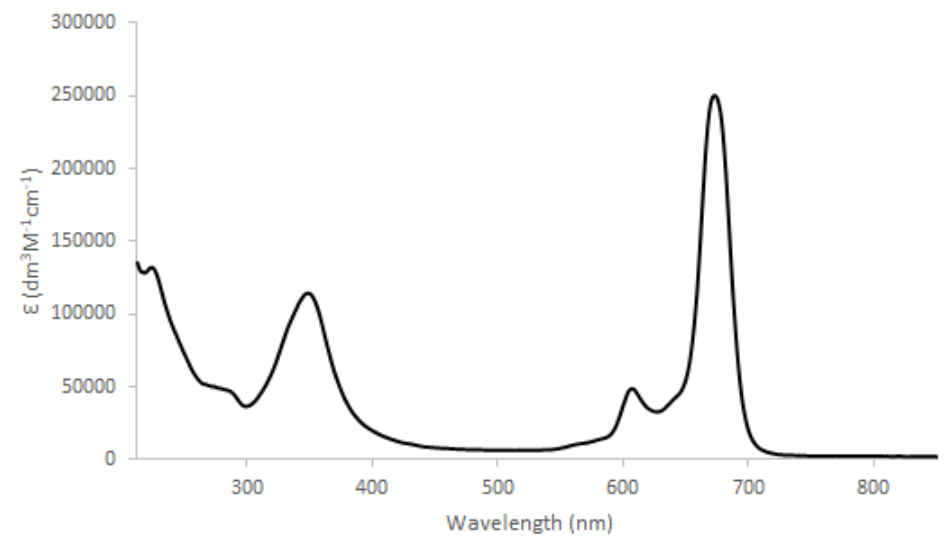

Figure S3. UV-Vis spectrum of TT1-amide-C3-azide (1) in THF (Concentration $\left.2,14 \cdot 10^{-6} \mathrm{M}\right)$. 

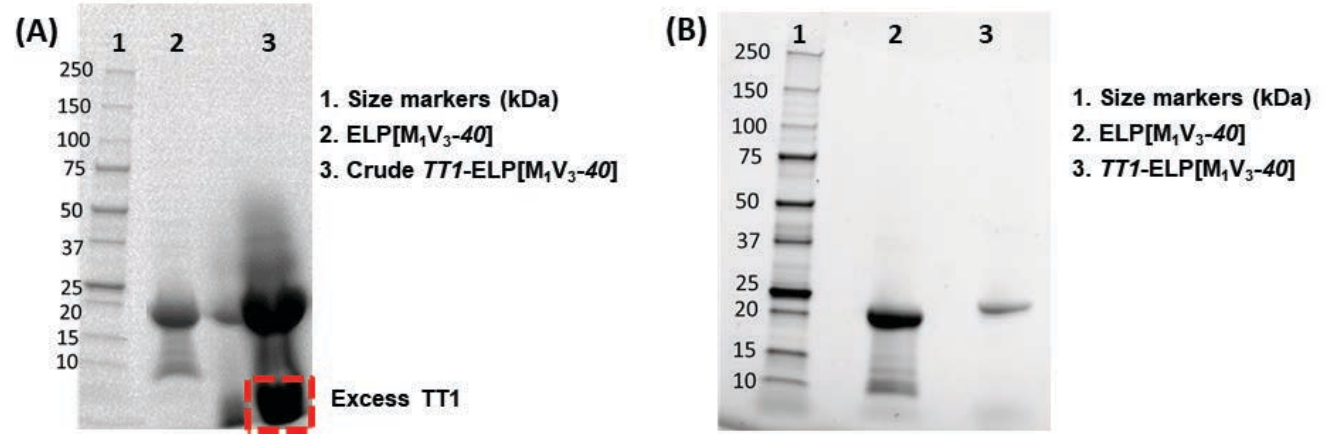

Figure S4. SDS-PAGE analysis of $T T 1-E L P\left[\mathrm{M}_{1} \mathrm{~V}_{3}-40\right]$ (A) before and (B) after purification.

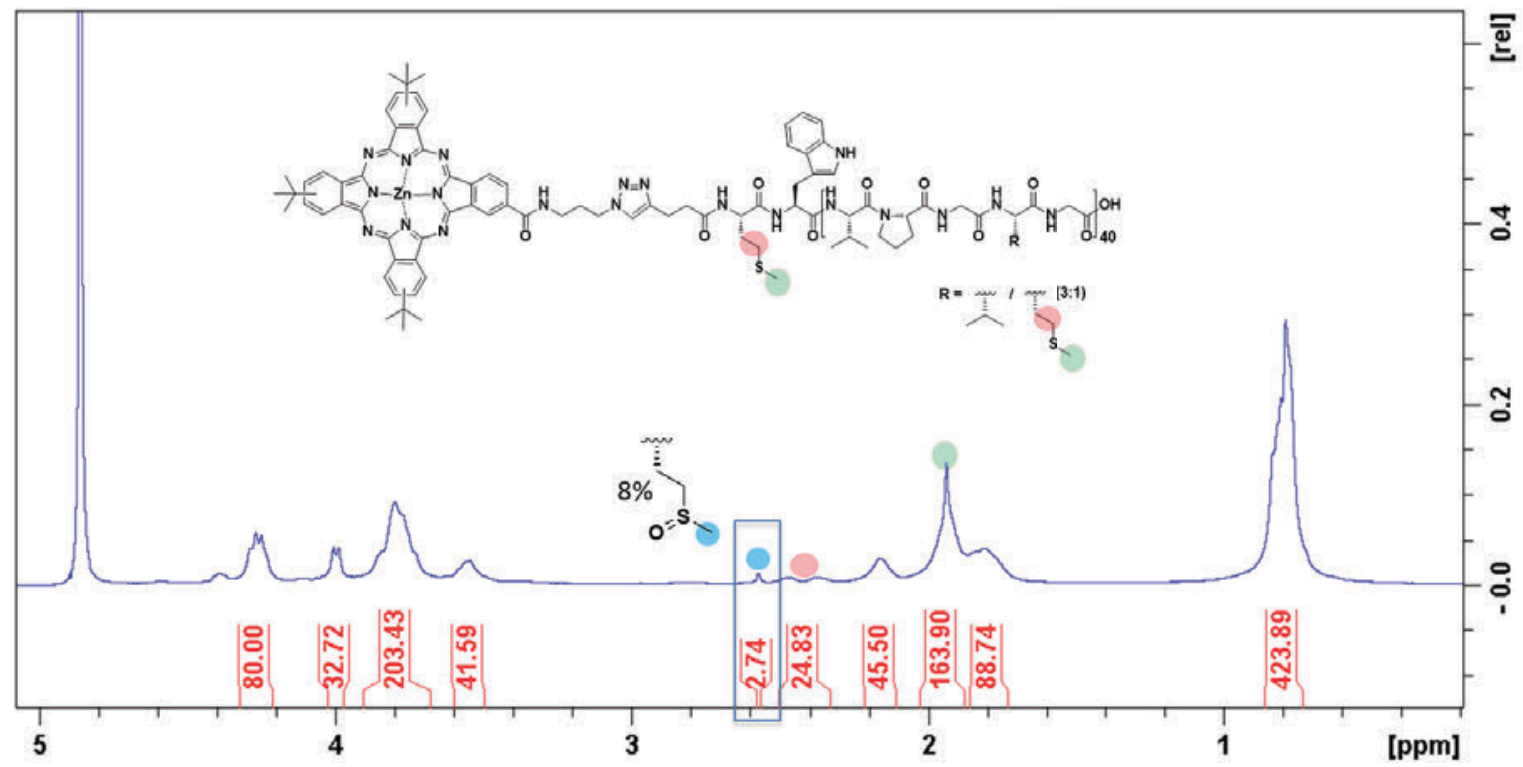

Figure S5. ${ }^{1} \mathrm{H}$ NMR spectrum of $T T 1$-ELP $\left[\mathrm{M}_{1} \mathrm{~V}_{3}-40\right]$ in $\mathrm{D}_{2} \mathrm{O}$ at $5{ }^{\circ} \mathrm{C}$. 


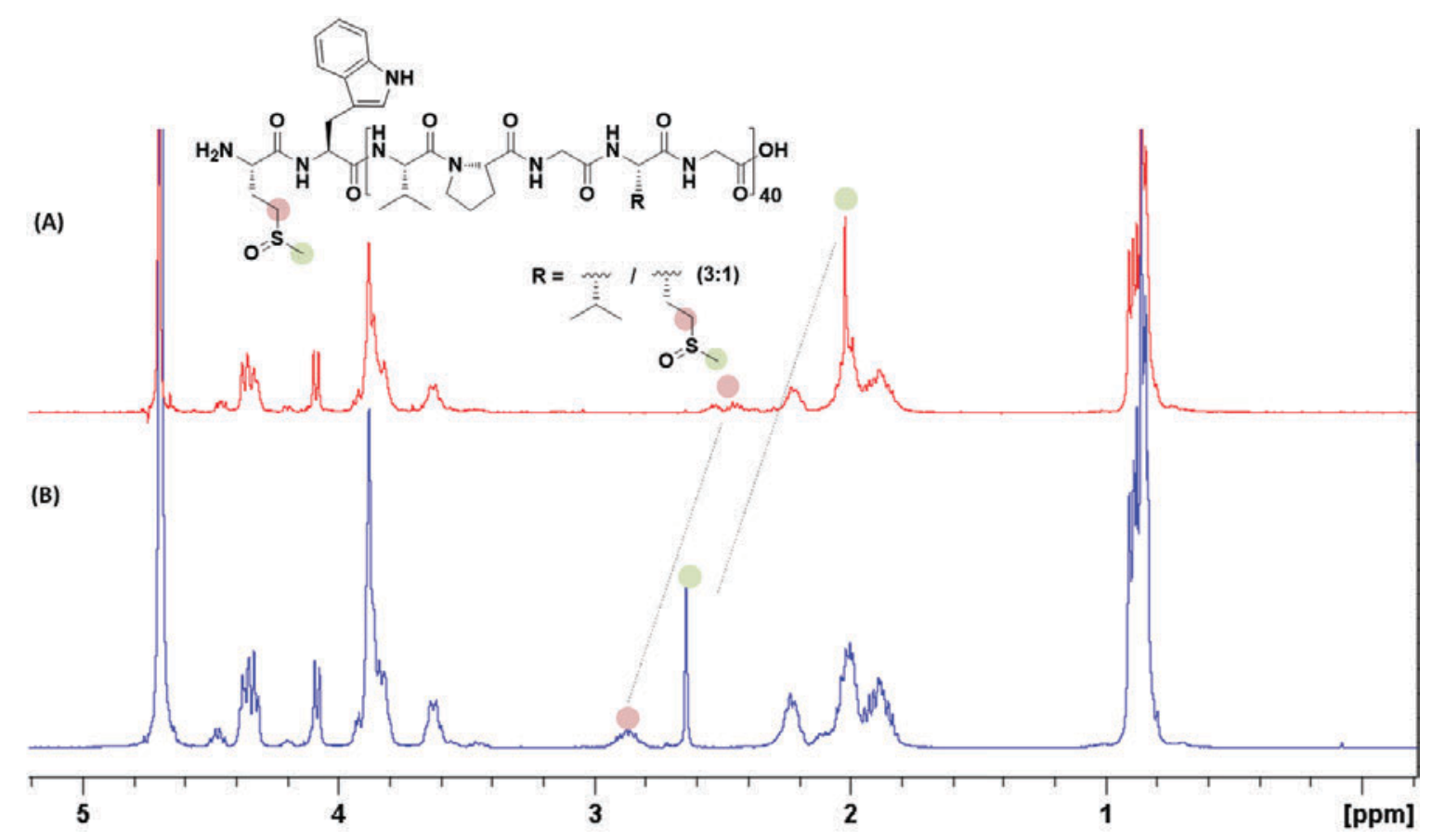

Figure S6. ${ }^{1} \mathrm{H}$ NMR spectrum of $\operatorname{ELP}\left[\mathrm{M}(O){ }_{1} \mathrm{~V}_{3}-40\right]$, (A) before and (B) after the chemical oxidation, in $\mathrm{D}_{2} \mathrm{O}$ at room temperature.

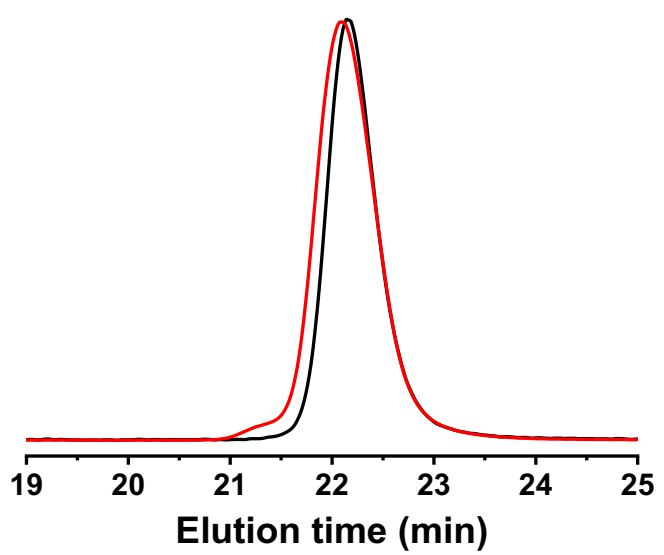

Figure S7. Size exclusion chromatograms (RI detection) in DMSO of ELP $\left[\mathrm{M}_{1} \mathrm{~V}_{3}-40\right]$ (black curve) and $\operatorname{ELP}\left[\mathrm{M}(O)_{1} \mathrm{~V}_{3}-40\right]$ (red curve). 


\section{N-terminal modification of ELP[M(O) $\left.{ }_{1} V_{3^{-}}-40\right]$}

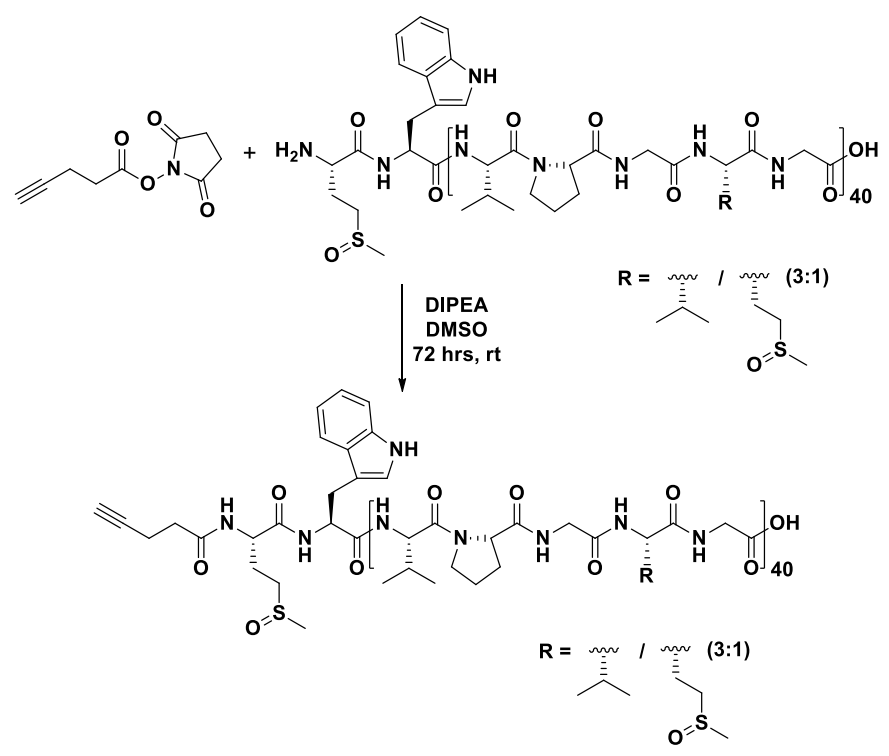

Scheme S2. Synthesis of Alkyne-ELP $\left[\mathrm{M}(O)_{1} \mathrm{~V}_{3}-40\right]$.

To a solution of ELP $\left[\mathrm{M}(O)_{1} \mathrm{~V}_{3}-40\right](40 \mathrm{mg}, 2.32 \mu \mathrm{mol})$ in anhydrous DMSO $(2 \mathrm{~mL}) \mathrm{N}, \mathrm{N}$ diisopropylethylamine $(0.3 \mathrm{mg}, 2.32 \mu \mathrm{mol})$ was added and followed by addition of 4-pentynoic acid succinimidyl ester $(9 \mathrm{mg}, 46.48 \mu \mathrm{mol})$. The reaction mixture was stirred for $72 \mathrm{~h}$ under Ar at room temperature. Then the solution was diluted with $15 \mathrm{~mL}$ of water and dialyzed against ultrapure water in a dialysis bag (cut-off MWCO $3.5 \mathrm{kDa}$ ) for $72 \mathrm{~h}$ by changing the water every 3h. The solution was lyophilized to yield Alkyne-ELP[M $\left.(O)_{1} \mathrm{~V}_{3}-40\right](30 \mathrm{mg}, 75 \%)$ as a white powder.

${ }^{1} \mathrm{H}$ NMR (400 MHz, $\mathrm{D}_{2} \mathrm{O}, 25^{\circ} \mathrm{C}$ ): $\delta$ 4.29-4.23 (m, $80 \mathrm{H}, \alpha \mathrm{CH}$ Val, Pro), 4.09-3.99 (d, $30 \mathrm{H}, \alpha \mathrm{CH}$ VPGVG), 2.85-2.73 (m, $22 \mathrm{H}, \mathrm{CH}_{2} \mathrm{~S} \mathrm{Met}$ ), 2.38-2.29 (br m, $\gamma \mathrm{CH}_{2} \mathrm{Met}, \mathrm{CH}_{2} \mathrm{CH}_{2} \mathrm{C} \equiv \mathrm{CH}$ ), 2.56 (s, $33 \mathrm{H}, \mathrm{SCH}_{3} \mathrm{Met}$ ), 0.82-0.75 (br m, $420 \mathrm{H}, \mathrm{CH}_{3} \mathrm{Val}$ ). 


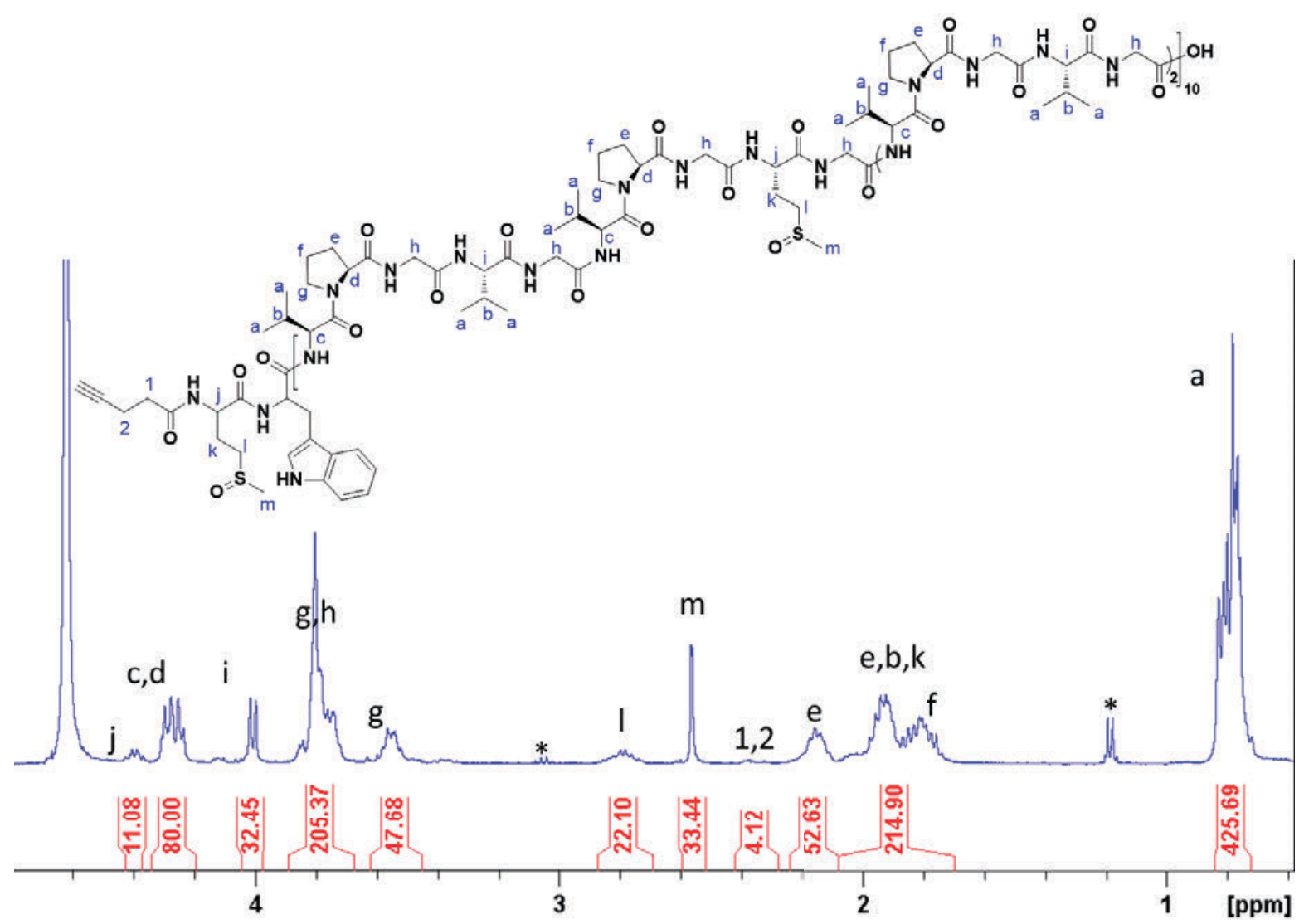

Figure S8. ${ }^{1} \mathrm{H}$ NMR spectrum of Alkyne-ELP $\left[\mathrm{M}(O)_{1} \mathrm{~V}_{3}-40\right]$ in $\mathrm{D}_{2} \mathrm{O}$ at room temperature $(* \mathrm{EtOH})$.

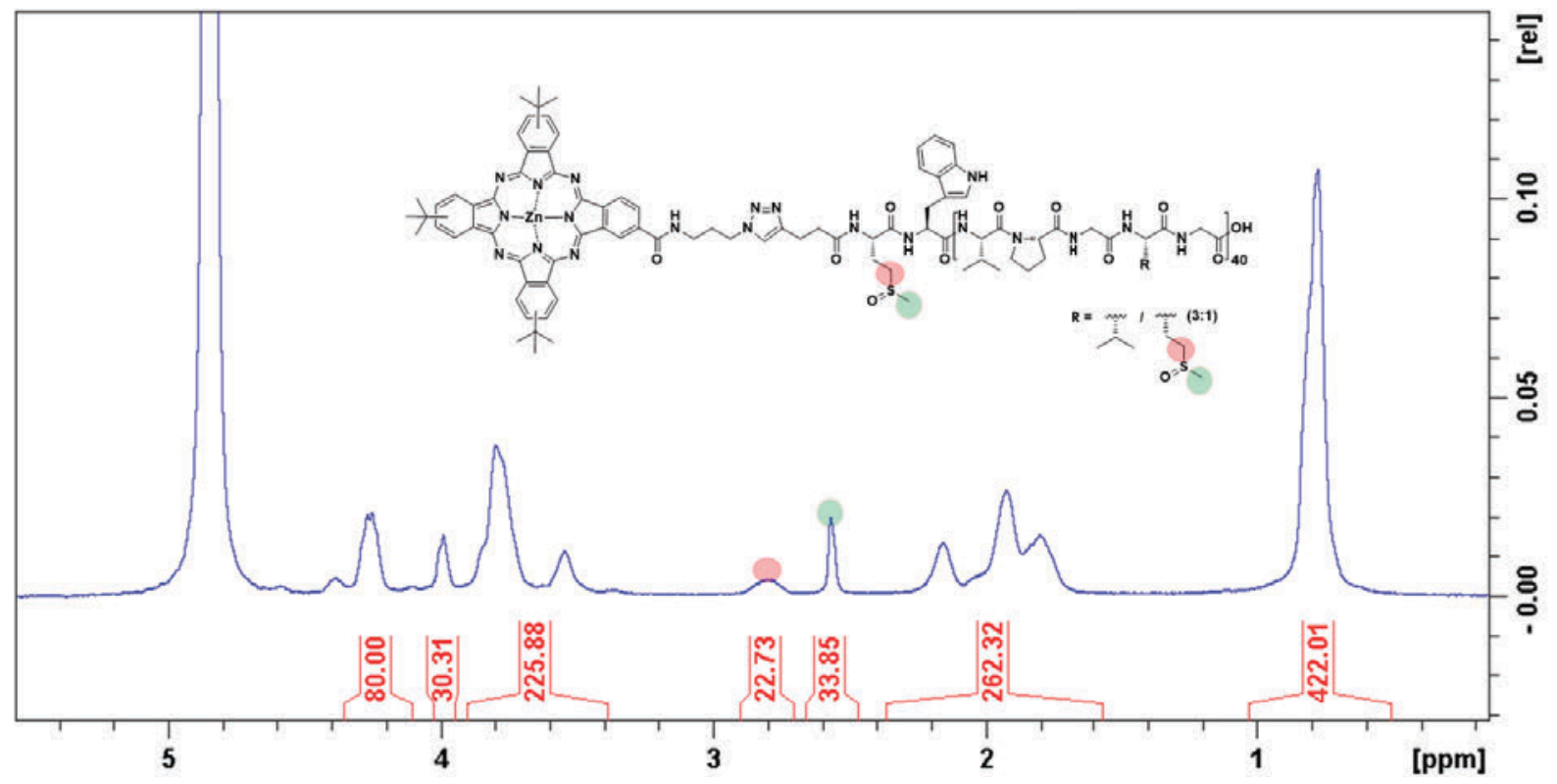

Figure S9. ${ }^{1} \mathrm{H}$ NMR spectrum of $T T 1$-ELP $\left[\mathrm{M}(O)_{1} \mathrm{~V}_{3}-40\right]$ in $\mathrm{D}_{2} \mathrm{O}$ at $5{ }^{\circ} \mathrm{C}$. 


\section{$10 \mu \mathrm{M}$ solutions in PBS}

$=-10$ to $65^{\circ} \mathrm{C}$

- 65 to $10^{\circ} \mathrm{C}$

(A)

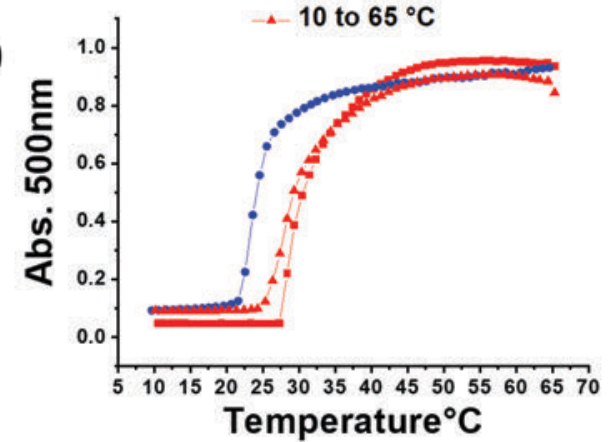

(B)

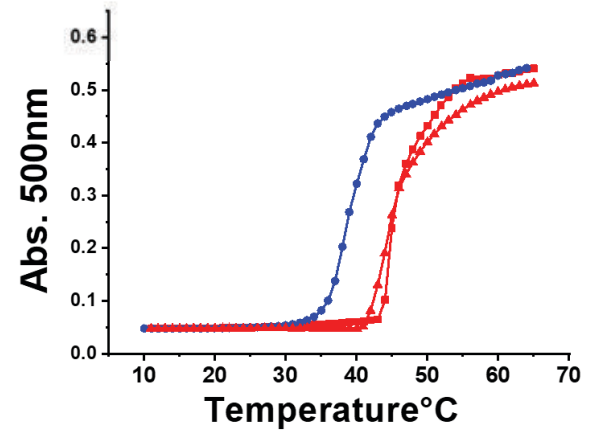

(C)

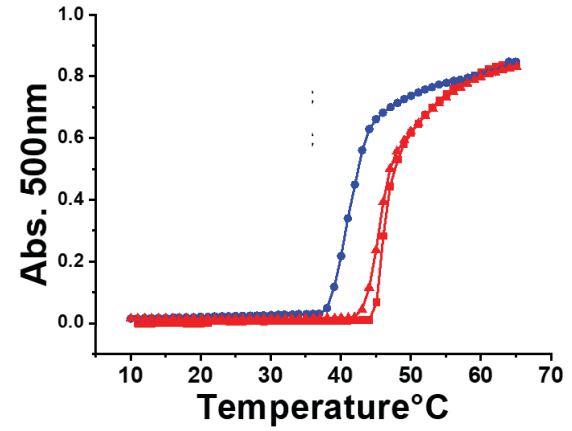

\section{Different concentration}

$-10 \mu \mathrm{M}$

$-20 \mu \mathrm{M}$

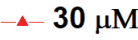
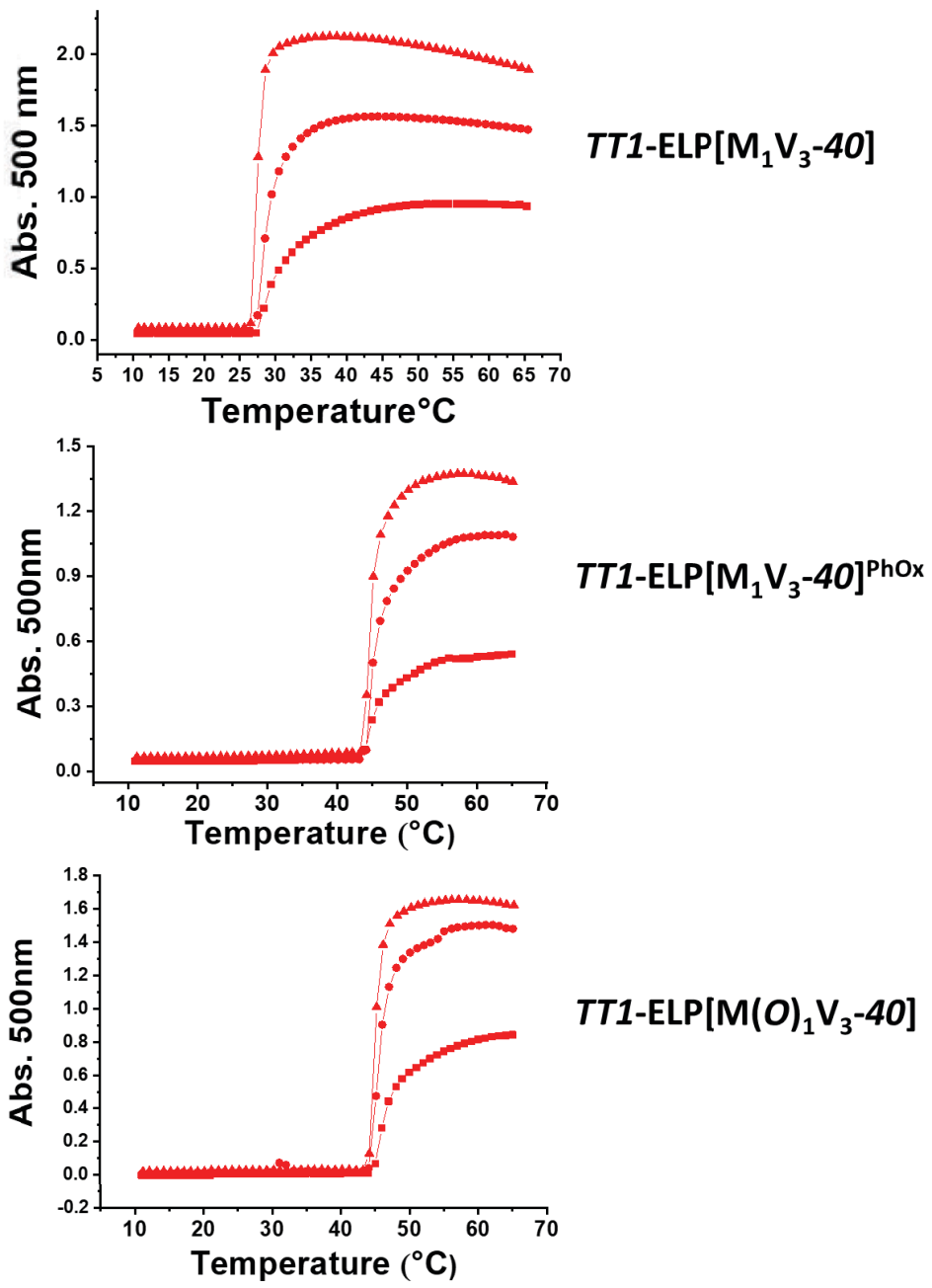

Figure S10. Absorbance (A.U.) at $500 \mathrm{~nm}$ of (A) TT1-ELP[M $\left.1 \mathrm{~V}_{3}-40\right]$, (B) TT1-ELP[M $\left.\mathrm{M}_{1} \mathrm{~V}_{3}-40\right]$ photooxidized, noted TT1-ELP $\left[\mathrm{M}_{1} \mathrm{~V}_{3}-40\right]^{\mathrm{PhOx}}$, and (C) TT1-ELP[M $\left.(O)_{1} \mathrm{~V}_{3}-40\right]$ solutions upon heating-cooling-heating $\left(10-65^{\circ} \mathrm{C}\right)$ cycles at $10 \mu \mathrm{M}$ (left panels) and upon heating at $10 \mu \mathrm{M}, 20$ $\mu \mathrm{M}$ and $30 \mu \mathrm{M}$ concentrations (right panels) in PBS as a function of temperature. 

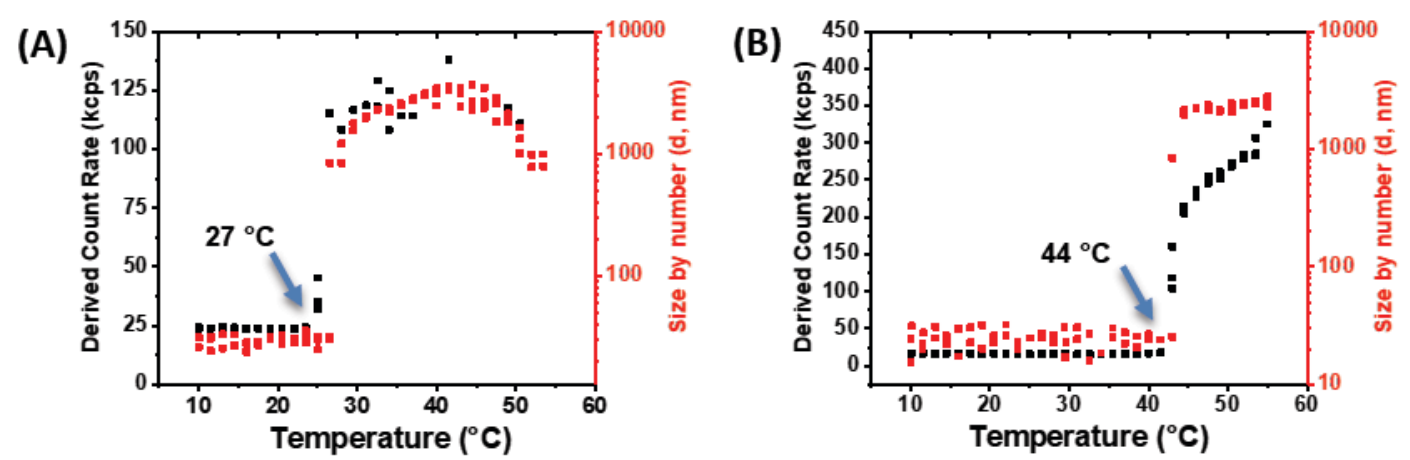

Figure S11. Temperature ramp results of (A) TT1-ELP $\left[\mathrm{M}_{1} \mathrm{~V}_{3}-40\right]$ and (B) TT1-ELP $\left[\mathrm{M}(O)_{1} \mathrm{~V}_{3}-40\right]$ solutions at $30 \mu \mathrm{M}$ concentration in PBS buffer upon heating at a range of $10-55^{\circ} \mathrm{C}\left(1.5^{\circ} \mathrm{C}\right.$ step, $\mathrm{n}=3$ ) measured by DLS at $90^{\circ}$ angle.

(A)
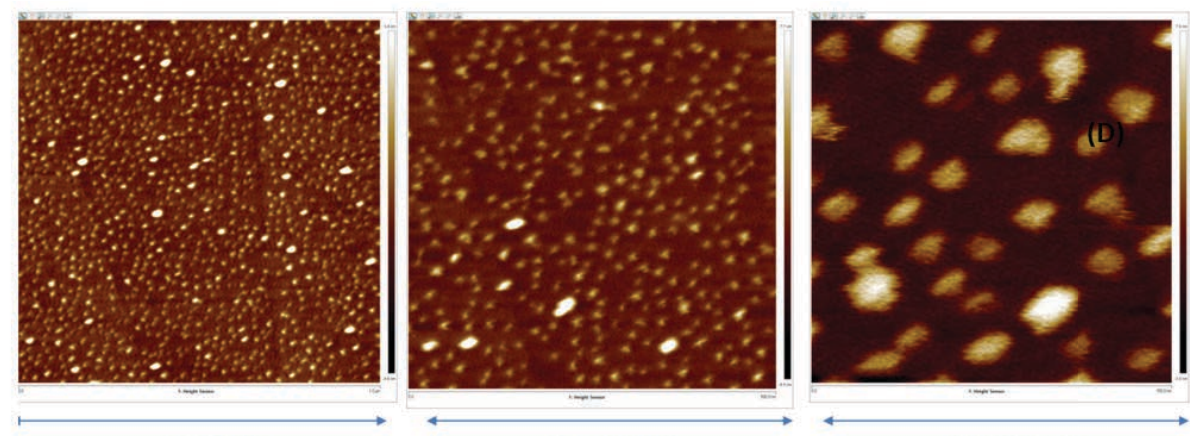

(B)

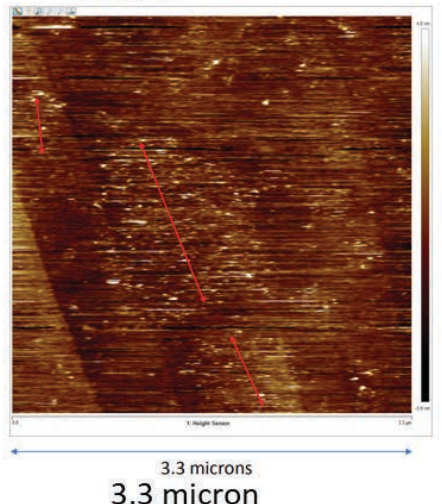

0.5 micron

0.15 micron

(C)

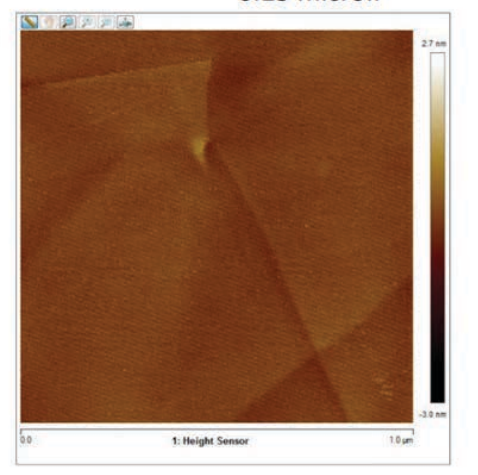

water on hopg substrate

Figure S12. Temperature-Controlled High-Speed AFM (liquid) images of TT1-ELP $\left[\mathrm{M}_{1} \mathrm{~V}_{3}-40\right]$ on HOPG substrate (A) at $15^{\circ} \mathrm{C},(\mathrm{B})$ at $50^{\circ} \mathrm{C}$ in PBS and (C) pure water on HOPG substrate. 


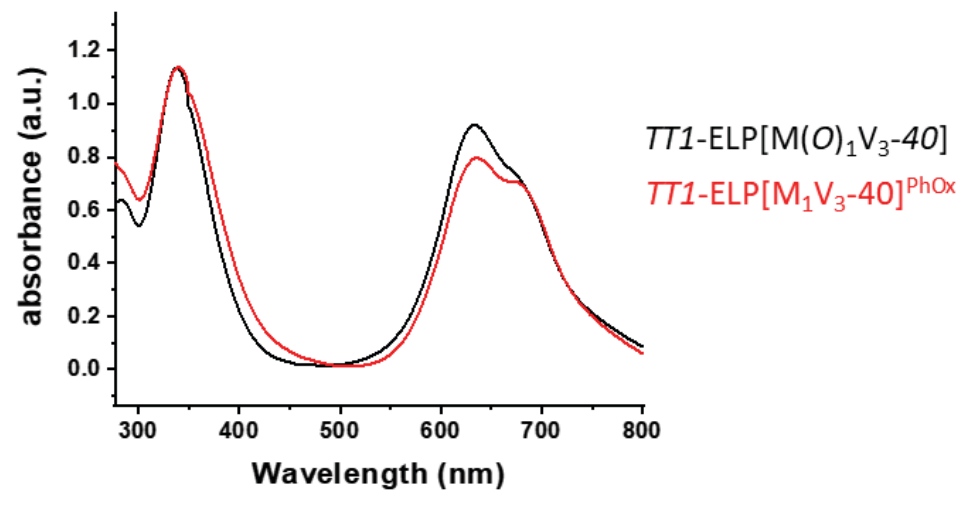

Figure S13. Overlapped absorption spectra of TT1-ELP $\left[\mathrm{M}(O)_{1} \mathrm{~V}_{3}-40\right]$ (black curve) and TT1$\mathrm{ELP}\left[\mathrm{M}_{1} \mathrm{~V}_{3}-40\right]^{\mathrm{PhOx}}$ (red curve) in water. 